\title{
Postnatal Fluoxetine Treatment Alters Perineuronal Net Formation and Maintenance in the Hippocampus
}

\author{
Sourish Mukhopadhyay, ${ }^{*}$ Ashmita Chatterjee, ${ }^{*}$ Praachi Tiwari, Utkarsha Ghai, and ${ }^{D}$ Vidita A. Vaidya
}

https://doi.org/10.1523/ENEURO.0424-20.2021

Department of Biological Sciences, Tata Institute of Fundamental Research, Mumbai 400005, India

\begin{abstract}
Elevation of serotonin via postnatal fluoxetine (PNFIx) treatment during critical temporal windows is hypothesized to perturb the development of limbic circuits thus establishing a substratum for persistent disruption of mood-related behavior. We examined the impact of PNFIx treatment on the formation and maintenance of perineuronal nets (PNNs), extracellular matrix (ECM) structures that deposit primarily around inhibitory interneurons, and mark the closure of critical period plasticity. PNFIx treatment evoked a significant decline in PNN number, with a robust reduction in PNNs deposited around parvalbumin (PV) interneurons, within the CA1 and CA3 hippocampal subfields at postnatal day (P)21 in Sprague Dawley rat pups. While the reduction in CA1 subfield PNN number was still observed in adulthood, we observed no change in colocalization of PV-positive interneurons with PNNs in the hippocampi of adult PNFIx animals. PNFIx treatment did not alter hippocampal PV, calretinin (CaIR), or Reelin-positive neuron numbers in PNFIx animals at P21 or in adulthood. We did observe a small, but significant increase in somatostatin (SST)-positive interneurons in the DG subfield of PNFIxtreated animals in adulthood. This was accompanied by altered GABA-A receptor subunit composition, increased dendritic complexity of apical dendrites of CA1 pyramidal neurons, and enhanced neuronal activation revealed by increased c-Fos-positive cell numbers within hippocampi of PNFIx-treated animals in adulthood. These results indicate that PNFIx treatment alters the formation of PNNs within the hippocampus, raising the possibility of a disruption of excitation-inhibition (E/I) balance within this key limbic brain region.
\end{abstract}

Key words: antidepressant; selective serotonin reuptake inhibitor; interneurons; parvalbumin; PNN

\section{Significance Statement}

Clinical and preclinical studies indicate that developmental exposure to fluoxetine programs persistent dysregulation of mood-related behaviors. This is hypothesized to involve the disruption of key brain regions, such as the hippocampus that regulate mood behaviors. We show that postnatal exposure to fluoxetine alters hippocampal perineuronal nets (PNNs), extracellular matrix (ECM) structures that regulate plasticity. The decline in PNNs is noted in early postnatal life, and persists into adulthood in specific hippocampal subfields. Adult animals with a history of postnatal fluoxetine (PNFIx) exposure exhibit altered numbers of somatostatin (SST) interneurons, GABA receptor subunit expression and neuronal activation within the hippocampus. Collectively our findings indicate that PNFIx treatment exerts both acute and persistent effects on hippocampal structure and neuronal activity.

\section{Introduction}

Selective serotonin reuptake inhibitors (SSRIs) are conventionally used as the first line of treatment for women

Received September 30, 2020; accepted January 28, 2021; First published February 23, 2021.

The authors declare no competing financial interests. with gestational and postpartum depression (Nonacs and Cohen, 2003; Kodish et al., 2011). Perinatal exposure to SSRIs has been linked to altered neurobehavioral

Author contributions: S.M., A.C., and V.A.V. designed research; S.M., A.C., P.T., and U.G. performed research; V.A.V. contributed unpublished reagents/ analytic tools; S.M., A.C., P.T., and U.G. analyzed data; S.M., A.C., and V.A.V. wrote the paper. 
development (Mulder et al., 2011; Glover and Clinton, 2016) and increased risk for suicidal ideation in children and adolescents (Cipriani et al., 2005). Preclinical studies investigating perinatal exposure to SSRIs report increased anxiety and despair-like behaviors in rodent models that persist across the life-span (Hilakivi and Hilakivi, 1987; Ansorge et al., 2004, 2008; Sarkar et al., 2014a). In addition to altering the development of emotionality, perinatal SSRI administration also evokes dysregulation of circadian rhythms and sleep (Mirmiran et al., 1981; Hilakivi et al., 1988; Vogel et al., 1990; Popa et al., 2008), alters cortical network function (Simpson et al., 2011), perturbs hormonal stress responses (Norcross et al., 2008), disrupts social play (Bond et al., 2020), reproductive and maternal care behavior (Svirsky et al., 2016), and alters the development of serotonergic circuitry (Weaver et al., 2010). Perinatal SSRI exposure alters hippocampal plasticity (Karpova et al., 2009), neurotrophic factor signaling (Rayen et al., 2015), and disrupts hippocampal neurogenesis in a sexually dimorphic manner (Gemmel et al., 2016). Given the extended developmental trajectory of the hippocampus and the key role it plays in emotional behavior (Rice and Barone, 2000), this limbic brain region that receives dense serotonergic innervation (Oleskevich and Descarries, 1990) is likely to be impacted by perinatal SSRI administration.

The hippocampus exhibits protracted development with neurogenesis, gliogenesis, cell-type specification, and synaptogenesis extending well into the juvenile window for rodents (Bayer, 1980). Preclinical models of early life stress are reported to evoke a decline in hippocampal neurogenesis (Naninck et al., 2015), dendritic atrophy (Champagne et al., 2008), enhanced cell death (Bath et al., 2016), and altered neurotrophic signaling in the hippocampus (Suri et al., 2014). These structural and functional changes in the hippocampus are implicated in mediating the sustained changes in mood-related behavior that arise as a consequence of early adversity (Fenoglio et al., 2006; Chen and Baram, 2016). The postnatal window marks an important period in hippocampal development and closure of this period is associated with the deposition of extracellular matrix (ECM) moieties, called perineuronal nets (PNNs), preferentially deposited around interneurons (Hensch, 2005). Maternal separation (MS)based models of early stress are reported to cause a decline of PNNs in the prelimbic (PrL) prefrontal cortex (PFC) in juvenile animals (Gildawie et al., 2020), and an increase

This work was supported by the Department of Atomic Energy, Government of India (DAE) Grant RTI4003 and the Department of Biotechnology, Government of India Grant BT/COE/34/SP17426/2016. We thank Dr. Shital Suryavanshi, Ms. K.V. Boby and the animal house staff at the Tata Institute of Fundamental Research (TIFR), Mumbai for technical assistance.

${ }^{*}$ S.M. and A.C. are equal contributing co-authors.

Correspondence should be addressed to Vidita A. Vaidya at vvaidya@ tifr.res.in.

https://doi.org/10.1523/ENEURO.0424-20.2021

Copyright (C) 2021 Mukhopadhyay et al.

This is an open-access article distributed under the terms of the Creative Commons Attribution 4.0 International license, which permits unrestricted use, distribution and reproduction in any medium provided that the original work is properly attributed. in PNN intensity around parvalbumin (PV) interneurons in the hippocampus in adults (Murthy et al., 2019). Chronic administration of SSRIs can also impact PNN deposition around PV cells, and is implicated in fear erasure in the basolateral amygdala (Karpova et al., 2011) and in the reopening of critical period plasticity in the visual cortex, likely through the dissolution of PNNs in adulthood (Maya Vetencourt et al., 2008). We hypothesized that SSRI administration during postnatal life could impact the formation and maintenance of PNNs in the hippocampus, a brain region reported to be highly sensitive to perturbations of serotonergic signaling.

In this study, we investigated the influence of postnatal fluoxetine (PNFIx) treatment on the formation of PNNs during postnatal life and their maintenance in adulthood. We addressed whether the number of PNNs that encapsulate PV-positive interneurons in distinct hippocampal subfields are altered as a consequence of PNFIx treatment, both at an early time point in postnatal life soon after cessation of the SSRI treatment and in adulthood. PNNs are known for the role they play in regulating synaptic physiology and receptor composition, and can thus impinge on neuronal excitation-inhibition (E/I) balance (Sorg et al., 2016; Fawcett et al., 2019). We also examined the influence of PNFIx treatment on interneuron numbers, NMDA and GABA receptor subunit composition, neuronal activity in the hippocampus and the cytoarchitecture of hippocampal pyramidal neurons. We find that PNFIx treatment results in reduced numbers of PNNs in the hippocampus and that this decline is maintained into adulthood in a hippocampal subfield-specific manner. This reduction in PNNs results in a significant decline in the number of PV cells ensheathed by PNNs. Additionally, we also observed an increase in neuronal activity within the hippocampus in animals with a history of PNFIx, associated with an altered subunit composition in GABA-A receptors, and a small but significant increase in the dendritic complexity noted in the distal regions of CA1 pyramidal neuron dendritic arbors. Taken together, our results indicate that chronic exposure to SSRls in the postnatal window alters the trajectory of PNN development, and has implications for the function of local inhibitory circuits in the hippocampus.

\section{Materials and Methods}

\section{Animals}

Sprague Dawley rats bred at the Tata Institute of Fundamental Research (TIFR) animal facility were used for all experiments. Animals were maintained on a 12/12 h light/ dark cycle (7 A.M. to 7 P.M.) with ad libitum access to food and water. Experimental procedures were conducted as per the guidelines of the Committee for the Purpose of Control and Supervision of Experiments on Animals (CPCSEA), Government of India and were approved by the TIFR animal ethics committee (TIFR/IAEC/2017-2).

\section{Drug treatments}

Litters derived from primiparous Sprague Dawley dams were assigned at random to either the vehicle or PNFIx 
administered treatment groups, with each treatment group containing pups obtained from four or more litters, to avoid any litter-specific effects. Rat pups received oral administration of fluoxetine $(10 \mathrm{mg} / \mathrm{kg}$; kind gift from IPCA Laboratories) or vehicle (5\% sucrose, Sigma-Aldrich) once daily through a micropipette $(0.5-10 \mu \mathrm{l}$, Eppendorf) from postnatal day $(P) 2$ to $P 21$, completed within 3 min of separation from the dam to minimize any handling related stress. Male rat pups were weaned between P25 and P30, following which they were housed in identical grouphousing conditions (three to four animals per cage).

\section{Immunohistochemistry}

Sprague Dawley male and female rat pups were killed at P21 and adult male rats were killed at P80 via transcardial perfusion with $4 \%$ paraformaldehyde. Harvested brains were sectioned on a VT1000S vibratome (Leica) to generate serial coronal sections $(40-\mu \mathrm{m}$ thickness). Six free floating sections, containing the hippocampus and the medial PFC (mPFC; $240 \mu \mathrm{m}$ apart), per animal were processed for each immunohistochemical staining. Sections were blocked in $10 \%$ horse serum made in $0.1 \mathrm{M}$ phosphate buffer with $0.3 \%$ Triton X-100 (PBTx) for $2 \mathrm{~h}$ followed by overnight incubation with the following primary antibodies: mouse anti-PV (1:1000, Sigma-Aldrich, P3088), goat anti-somatostatin (SST; 1:350, Santa Cruz, SC-7819), goat anti-calretinin (CalR; 1:1000, Santa Cruz, SC-26512), mouse anti-Reelin (1:1000, Sigma-Aldrich, MAB5364), and rabbit anti-c-Fos (1:1000, Cell Signaling Technology, \#2250) in 0.3\% PBTx, at room temperature. After washes, the sections were incubated with secondary antibody solutions of biotinylated horse anti-mouse (1:500, Vector Laboratories, BA2000), biotinylated donkey anti-rabbit (1:500, Millipore, AP182B), and biotinylated rabbit anti-goat (1:500, Millipore, AP106) in 0.3\% PBTx for $3 \mathrm{~h}$. Subsequently, sections were incubated with avidin-biotin complex (Vector Labs, PK-6100) in 0.1 M PB for $1.5 \mathrm{~h}$ and visualized with diaminobenzidine staining (SigmaAldrich, D4293). To detect PNNs, sections were incubated with the plant lectin, biotinylated Wisteria floribunda (WFA; 1:250, Vector Laboratories, B1355) in 0.3\% PBTx overnight, followed by incubation with secondary antibody solution of Alexa Fluor 488-conjugated donkey anti-streptavidin (1:500, Invitrogen, S11223) for $3 \mathrm{~h}$. For double immunostainings of $P V$ and $P N N$, sections were incubated with primary antibody solution of rabbit anti-PV (1:1000) and biotinylated WFA (1:250) in $0.3 \%$ PBTx overnight followed by incubation with secondary antibody solutions of Alexa Fluor 488-conjugated donkey anti-streptavidin (1:500) and Alexa Fluor 555-conjugated donkey anti-rabbit (1:500, Invitrogen, A31572) for $3 \mathrm{~h}$.

\section{Cell visualization and counting}

Immunostained sections were mounted on glass slides with DPX mountant medium (Merck, 100579). Slides were coded and quantification was conducted by the experimenter blind to the treatment groups. Cells were visualized at $20 \times$ magnification using a bright field microscope (Zeiss Axioscope 2). For cell counting analysis in the subfields of the hippocampus, total number of stained cells were counted per animal per hippocampal subfield, namely the CA1, CA3, and DG, across representative sections taken from both the dorsal and ventral hippocampus, and divided by the number of sections to obtain an average number of cells per section within the respective hippocampal subfield. For cell counting analysis in the subdivisions of the mPFC, cells were visualized at $10 \times$ magnification in the infralimbic (IL), PrL, and cingulate (Cg) subdivisions, and images were taken using a Zeiss Axiocam camera. Cell numbers were counted manually using ImageJ (National Institutes of Health) by an experimenter blinded to the treatment conditions. For PV and PNN double immunofluorescence, sections spanning the rostro-caudal axis of the hippocampus from each animal were mounted on glass slides with Vectashield Hard-set Antifade mounting media with DAPI (Vector Labs, H1500). Slides were coded and quantification was conducted by the experimenter blind to the treatment groups. Cells were visualized at $20 \times$ magnification and images were acquired using Zeiss Axio Imager M2 (Zeiss). The percent colocalization of PV-positive cells with the PNN marker WFA was determined in the DG, CA1, CA3 hippocampal subfield in six sections ( $240 \mu \mathrm{m}$ apart) per animal. A minimum of 50 PV-positive cells were analyzed per animal using z-plane sectioning $(0.5 \mu \mathrm{m})$ to confirm the percent colocalization of PV with the PNN marker WFA.

\section{Quantitative PCR (qPCR)}

Vehicle and PNFIx treatment groups were subjected to qPCR analysis at two time points, namely P21, $2 \mathrm{~h}$ after cessation of the final fluoxetine/vehicle treatment and in adulthood (P100). The hippocampus was micro-dissected, snap-frozen using liquid nitrogen, and stored at $-80^{\circ} \mathrm{C}$. RNA was extracted using TRIzol reagent (Thermo Fisher Scientific) and reverse transcribed using cDNA synthesis kit (PrimeScript first strand cDNA Synthesis kit, Takara Bio). The synthesized cDNA was subjected to qPCR using KAPA SYBR (KAPA Biosystems) and a Bio-Rad CFX96 real-time PCR machine. Primers were designed using the NCBI primer BLAST program. The complete list of primers used is provided in Table 1. Hypoxanthine phosphoribosyltransferase 1 (Hprt-1) was used as the housekeeping gene for normalization.

\section{Western botting}

Sprague Dawley male and female pups were killed at P21 and adult male Sprague Dawley rats were killed on P100 and their hippocampi were dissected, snap-frozen in liquid nitrogen, and stored at $-80^{\circ} \mathrm{C}$. Tissue homogenization and protein extraction were performed in radioimmunoprecipitation assay buffer [10 mm Tris- $\mathrm{Cl}(\mathrm{pH} 8.0), 1$ mм EDTA, 0.5 mм EGTA, 1\% Triton $X-100$, 0.1\% sodium deoxycholate, 0.1\% SDS, $140 \mathrm{~mm} \mathrm{NaCl}$. Protease inhibitor cocktail (Sigma-Aldrich, P8340), phosphatase inhibitor cocktail 2 (Sigma-Aldrich, P5276), and phosphatase inhibitor cocktail 3 (Sigma-Aldrich, P0044) were added to the extraction buffer before protein extraction. Protein concentrations were estimated using a Quantipro BCA assay kit (Sigma-Aldrich). Protein lysates $(50 \mu \mathrm{g})$ were 
Table 1: Primer sequences (5'-3')

\begin{tabular}{|c|c|c|}
\hline Gene & Forward primer sequence & Reverse primer sequence \\
\hline aggrecan & CCTCAGAGGTGAATGTTACCG & TGGAGAAGCAAGGGTAGGG \\
\hline brevican & CTTTCCCCGAGTCAAATGG & TAGACCCCGGAATCATTGG \\
\hline hapln1 & ACCAGGATGCTGTGATTGC & TCCCAGAACCCGTAGTTCC \\
\hline hapln2 & GCGTGCCTATCAACTGTGC & TGAATGACCTCGTGGATGG \\
\hline $\operatorname{cspg} 4$ & CTGGAGAGAGGTGGAAGAGCAG & AACAGGGAGGATGGTGATAGTG \\
\hline has1 & GTGCTCACGATCACCTTCG & TTCGGTGCTCCAGGTAAGC \\
\hline has2 & GCAGGAGCTGAACAAGATGC & TTGGATGATGAGGTGTGAGG \\
\hline has3 & GATCGGCACCTTACCAACC & CCACAGGTGGTGCTTATGG \\
\hline chst3 & TCGCTTTGCCTCAGGATTGC & GCTTGTCGGAGACCCTGGATA \\
\hline chst7 & CCCGGGGCATATCTAGGTCA & CTGTGCAGCCTCTTCAGTGT \\
\hline chst11 & CAGAATTTGCCGGATGGTGC & GGATTCCTCCGCATGACTGG \\
\hline$m m p 2$ & CCAGAGACTGCTATGTCCACT & ACACCACACCTTGCCATCG \\
\hline mmp9 & CATCTGTATGGTCGTGGCTCT & CTGTCGGCTGTGGTTCAG \\
\hline
\end{tabular}

resolved on an SDS-PAGE system and transferred onto polyvinylidene fluoride membranes. The membranes were blocked using $5 \%$ bovine serum albumin (BSA; SigmaAldrich, A9418) in Tris-buffered saline with $0.1 \%$ of Tween 20 (TBST) followed by incubation with the primary antibodies, namely rabbit anti-NR2A (1:1000, Millipore, 07632), rabbit anti-NR2B (1:1000, Millipore, 06-600), rabbit anti-GABA-Aa1 (1:1000, Abcam, ab33299), mouse antiGABA-Aa2 (1:1000, Abcam, ab193311), and rabbit anti$\beta$-Actin (1:10,000, ABclonal, AC026) in TBST with 5\% $\mathrm{BSA}$ overnight at $4^{\circ} \mathrm{C}$. Following washes the blots were incubated with horseradish peroxidase (HRP)-conjugated goat anti-rabbit (1:5000, ABclonal, AS014) or HRP-conjugated goat anti-mouse (1:5000, ABclonal, AS003) for $2 \mathrm{~h}$. Visualization of the signal was performed with a Western blotting detection kit (SuperSignal West Pico Plus, Thermofisher, 34579) using the GE GE Healthcarelmager 600 (GE Life Sciences). Densitometric analysis of the blots were performed using ImageJ.

\section{Golgi staining and arborization analysis}

Male Sprague Dawley rats were killed in adulthood at P120 and their brains were harvested and Golgi staining was conducted using the FD Rapid GolgiStain kit (PK401) as per the manufacturer's instructions. Each brain was cut coronally into a smaller chunk containing the entire hippocampus and incubated with the impregnation solution in the dark for $21 \mathrm{~d}$. After impregnation, the brains are placed in a staining solution for $3 \mathrm{~d}$. Sections $(150 \mu \mathrm{m})$ were cut on a vibratome (Leica) and incubated with freshly prepared staining solutions as per the instructions in the FD Rapid GolgiStain kit for 10 min. After washes, the sections on slides were dehydrated using xylene, and mounted with DPX mountant medium. For tracing of neurons, slides were coded and quantification was conducted by an experimenter blind to the treatment groups.
Tracing of CA1 pyramidal neurons was conducted at $20 \times$ magnification on the BX53 light microscope (Olympus) using the Neurolucida 10 (MBF Biosciences). For Sholl analysis of neuronal traces, the Neurolucida 10 Explorer (MBF Biosciences) was used.

\section{Statistical analysis}

All experiments had two treatment groups and were subjected to the Shapiro-Wilk test to determine normality of the data. Data that followed a normal distribution were subjected to a two-tailed, unpaired Student's $t$ test using GraphPad Prism (GraphPad Software Inc.), and Welch's correction was applied when variances varied significantly between the treatment groups. Data that did not exhibit a normal distribution were subjected to the Mann-Whitney $U$ test. Graphs were plotted using GraphPad Prism. Data are expressed as mean \pm SEM, and statistical significance was set at $p<0.05$. For the arborization analysis, Friedman's test of repeated measures for non-parametric distributions was performed for Sholl analysis, and results were considered significant at $p<0.05$. A detailed statistical summary for all figures is provided in Tables 2, 3, and boldface in the table indicates $p<0.05$.

\section{Results}

\section{PNFIx treatment alters PNN numbers in the hippocampus}

PNNs are ECM-based structures that play a key role in the maturation of neuronal circuits, and are known to exhibit substantial alterations in response to environmental perturbations during critical period windows (Sorg et al., 2016). To study the effects of PNFIx exposure on PNNs in the hippocampal subfields, we orally administered fluoxetine to rat pups from P2 to P21 (Figs. 1A, 2A). At P21 and in adulthood, we examined the expression of 
Table 2: Statistical table (except for Fig. 3)

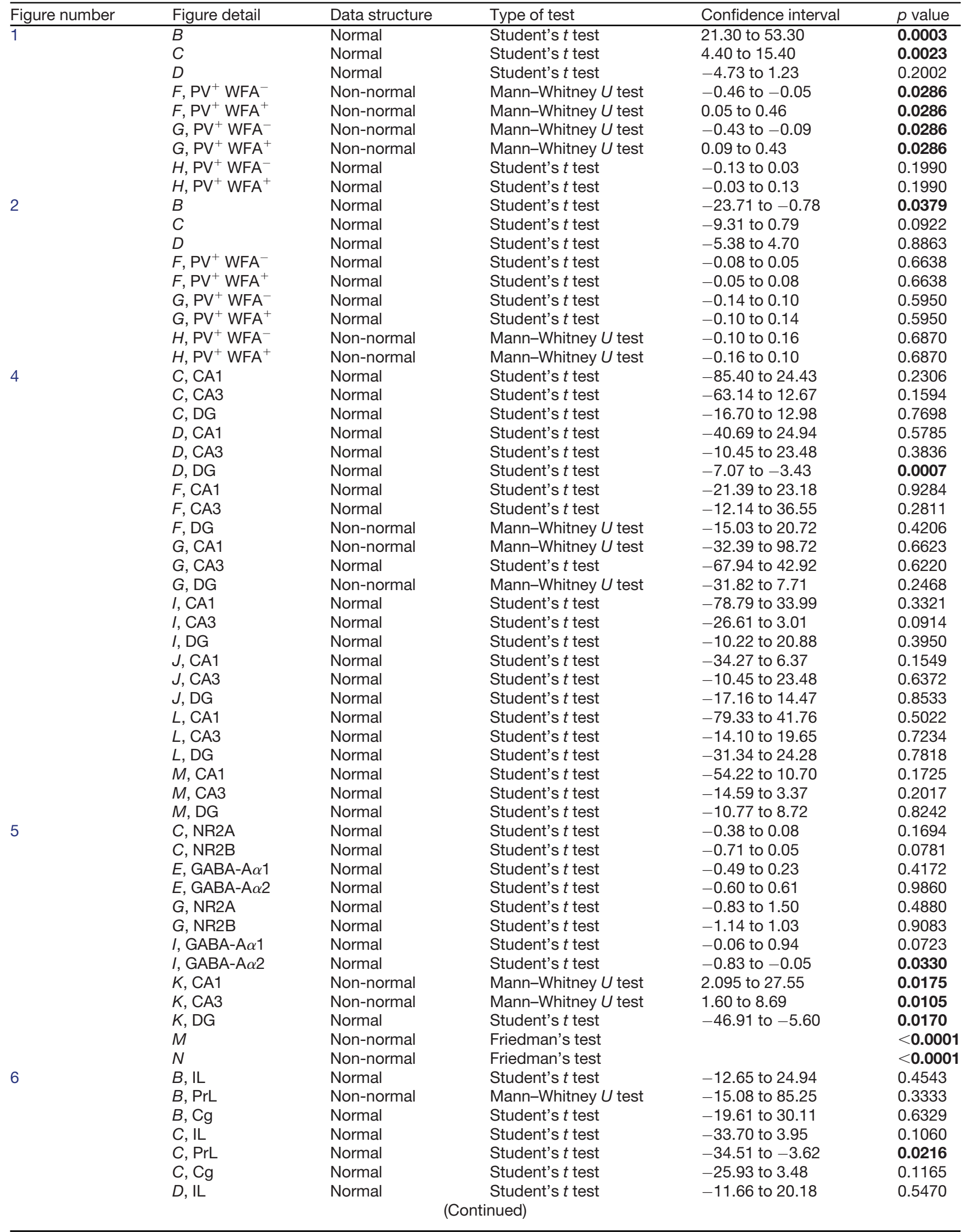


Table 2: Continued

\begin{tabular}{|c|c|c|c|c|c|}
\hline Figure number & Figure detail & Data structure & Type of test & Confidence interval & $p$ value \\
\hline & $D, \operatorname{PrL}$ & Normal & Student's $t$ test & -30.25 to 10.09 & 0.2825 \\
\hline & $D, \mathrm{Cg}$ & Normal & Student's $t$ test & -24.61 to 37.61 & 0.6428 \\
\hline & $E, \mathrm{IL}$ & Normal & Student's $t$ test & -14.26 to 14.24 & 0.9986 \\
\hline & $E, \operatorname{PrL}$ & Normal & Student's $t$ test & -2.37 to 24.83 & 0.0946 \\
\hline & $E, \mathrm{Cg}$ & Normal & Student's $t$ test & -22.92 to 12.49 & 0.5218 \\
\hline & $F, \mathrm{IL}$ & Normal & Student's $t$ test & -4.41 to 6.75 & 0.6418 \\
\hline & $F, \operatorname{PrL}$ & Normal & Student's $t$ test & -9.10 to 10.10 & 0.9078 \\
\hline & $F, \mathrm{Cg}$ & Normal & Student's $t$ test & -7.95 to 8.35 & 0.9562 \\
\hline & G, IL & Normal & Student's $t$ test & -12.13 to 6.43 & 0.4995 \\
\hline & G, PrL & Non-normal & Mann-Whitney $U$ test & -5.73 to 13.55 & 0.5476 \\
\hline & $\mathrm{G}, \mathrm{Cg}$ & Normal & Student's $t$ test & -8.17 to 12.16 & 0.6624 \\
\hline & $I, \mathrm{IL}$ & Normal & Student's $t$ test & -19.31 to 7.74 & 0.3456 \\
\hline & $I, \operatorname{PrL}$ & Normal & Student's $t$ test & -17.93 to 13.13 & 0.7257 \\
\hline & $\mathrm{I}, \mathrm{Cg}$ & Normal & Student's $t$ test & -20.41 to 13.74 & 0.6582 \\
\hline & $K, \mathrm{IL}$ & Non-normal & Mann-Whitney $U$ test & -18.57 to 1.24 & 0.1605 \\
\hline & $K, \operatorname{PrL}$ & Normal & Student's $t$ test & -15.33 to -1.79 & 0.0171 \\
\hline & $K, \mathrm{Cg}$ & Normal & Student's $t$ test & -20.59 to -3.42 & 0.0098 \\
\hline
\end{tabular}

WFA, a plant lectin that binds to the sugar moieties present on the PNNs (Brückner et al., 1996), to visualize PNN numbers. This allowed us to address the short and long-term influence of elevation of serotonin levels during the postnatal temporal window via PNFIx treatment on both the formation and maintenance of PNNs in the hippocampus.

At P21, we observed a robust decline in the number of WFA-stained PNNs in the CA1 $(p=0.0003, n=6-7$ per group; Fig. $1 B$ ) and CA3 $(p=0.0023, n=6-7$ per group; Fig. 1C) hippocampal subfields in PNFIx animals compared with the vehicle-treated controls. In contrast, we noted no difference in the number of PNNs detected within the DG subfield (Fig. 1D). PNNs condense primarily around local GABAergic PV-positive interneurons across numerous cortical and subcortical regions, restricting extensive experience-dependent remodeling within these circuits (Hensch, 2004). We next analyzed whether PNFIx treatment influenced the fraction of hippocampal PV-positive interneurons that were surrounded by PNNs (Fig. 1E) at the early time point of P21. We find a significantly smaller fraction of PV-positive neurons surrounded by PNNs in the CA1 (PNN/PV $V_{\text {Vehicle/CA1 }}=53.25 \%, \mathrm{PNN}_{\mathrm{PV}} \mathrm{PNFIx} / \mathrm{CA} 1=$ $23.25 \% ; p=0.0286, n=4$ per group; Fig. $1 F$ ) and CA3 $\left(\mathrm{PNN} / \mathrm{PV}_{\text {Vehicle/CA3 }}=46.75 \%, \mathrm{PNN} / \mathrm{PV}_{\mathrm{PNFIX} / \mathrm{CA} 3}=15.75 \%\right.$; $p=0.0286, n=4$ per group; Fig. $1 G$ ) subfields of PNFIxtreated animals than in the vehicle-treated controls. Within the DG subfield, we noted no change in the colocalization of PV-positive neurons with WFA-positive PNNs as a consequence of PNFIx treatment (Fig. $1 H$ ). Our results indicate that there are marked changes in the total numbers of PNNs, as well as in the colocalization of PVpositive neurons with PNNs, within specific hippocampal subfields immediately after the cessation of PNFIx treatment.

We next sought to address whether the decline in PNN numbers noted in specific hippocampal subfields with PNFIx treatment at P21 persists into adulthood. We find that the CA1 hippocampal subfield of PNFIx animals continued to exhibit a deficit in the total number of PNNs $(p=0.0379, n=8$ per group; Fig. $2 B$ ). In contrast, the number of PNNs in the CA3 hippocampal subfield in the PNFIx cohort did not differ from vehicle-treated controls, indicating that the decline noted in PNN numbers in this subfield at $\mathrm{P} 21$ had shown substantial recovery by adulthood (Fig. $2 C)$. There was no difference in the number of PNNs in the DG hippocampal subfield in adulthood in the PNFIx cohort (Fig. 2D). We did not observe a difference in the proportion of PV-positive neurons that were surrounded by PNNs in either the CA1, CA3, or DG hippocampal subfield (Fig. 2F-H). We noted that the WFA-stained PNNs in adulthood (Fig. 2E) were better formed and showed a more prominent structure as compared with those at P21 (Fig. 1E). This is consistent with age-dependent maturation of the PNN structure that has been reported in many areas of the brain previously (Pizzorusso et al., 2002; Lipachev et al., 2019). Our results suggest that a transient elevation of serotonin in the postnatal temporal window alters the time course of the appearance and maturation of PNNs around PV-positive neurons in a subfield-specific manner in the hippocampus.

\section{PNFIx treatment alters PNN associated gene expression in the hippocampus}

We next addressed whether the transcription of PNN components or molecular machinery that is known to enzymatically modulate the ECM were specifically altered as a consequence of PNFIx treatment. We performed qPCR analysis on hippocampal lysates from PNFIx-treated and vehicle-treated animals at P21 and in adulthood to examine potential short and long-term changes in the expression of multiple genes associated with ECM composition, synthesis, proteolytic breakdown, sulfation levels and PNN-linked plasticity (Fig. $3 A, B$ ). We examined the expression of genes that encode PNN components (aggrecan, neurocan, brevican, versican; hyaluronan and proteoglycan link proteins, hapln1, hapln2; chondroitin sulfate proteoglycan, cspg4, tenascin $c$, and tenascin r), enzymatic machinery associated 
Table 3: Statistical table for Figure 3

\begin{tabular}{|c|c|c|c|c|c|c|c|c|c|}
\hline \multirow[b]{2}{*}{ Gene } & \multicolumn{9}{|c|}{$\mathrm{P} 21$} \\
\hline & $\begin{array}{l}\text { Data } \\
\text { structure }\end{array}$ & Type of test & $\begin{array}{l}\text { Confidence } \\
\text { interval }\end{array}$ & $p$ value & $t$ statistic & $\begin{array}{l}\text { Degrees of } \\
\text { freedom }\end{array}$ & U score & $\begin{array}{l}\text { Median and } \\
n \text { of vehicle }\end{array}$ & $\begin{array}{l}\text { Median and } \\
n \text { of PNFIx }\end{array}$ \\
\hline aggrecan & Normal & Student's $t$ test & -0.45 to 0.36 & 0.8008 & 0.2585 & 11 & - & - & - \\
\hline neurocan & Normal & Student's $t$ test & -0.72 to 0.13 & 0.1531 & 1.535 & 11 & - & - & - \\
\hline brevican & Normal & Student's $t$ test & -0.73 to 0.29 & 0.3640 & 0.9469 & 11 & - & - & - \\
\hline versican & Normal & Student's $t$ test & -0.64 to 0.09 & 0.1301 & 1.636 & 11 & - & - & - \\
\hline hapln1 & Non-normal & Mann-Whitney $U$ test & -0.54 to 0.21 & 0.8357 & - & - & 19 & $0.9922 n=6$ & $0.9661 n=7$ \\
\hline hapln2 & Normal & Student's $t$ test & -0.60 to 0.26 & 0.4059 & 0.8643 & 11 & - & - & - \\
\hline cspg 4 & Normal & Student's $t$ test & -0.39 to 0.21 & 0.5284 & 0.6510 & 11 & - & - & - \\
\hline tenascin c & Non-normal & Mann-Whitney $U$ test & -0.48 to 0.37 & 0.9452 & - & - & 20 & $\begin{array}{r}1.104 \\
n=6\end{array}$ & $1.065 n=7$ \\
\hline tenascin $r$ & Non-normal & Mann-Whitney $U$ test & -1.04 to 0.09 & 0.1014 & - & - & 9 & $0.7689 n=6$ & $0.6551 n=7$ \\
\hline has1 & Normal & Student's $t$ test & -0.35 to 0.40 & 0.8841 & 0.1492 & 11 & - & - & - \\
\hline has2 & Non-normal & Mann-Whitney $U$ test & -0.30 to 0.20 & 0.6282 & - & - & 17 & $1.021 n=6$ & $1.085 n=7$ \\
\hline has3 & Normal & Student's $t$ test & -0.40 to 0.19 & 0.4629 & 0.7606 & 11 & - & - & - \\
\hline chst3 & Non-normal & Mann-Whitney $U$ test & -0.06 to 0.80 & 0.0653 & - & - & 22 & $0.8176 n=10$ & $1.359 n=9$ \\
\hline chst7 & Normal & Student's $t$ test & 0.05 to 1.30 & 0.0352 & 2.288 & 17 & - & - & - \\
\hline chst11 & Normal & Student's $t$ test & -0.29 to 1.04 & 0.2480 & 1.196 & 17 & - & - & - \\
\hline chst12 & Normal & Student's $t$ test & 0.09 to 1.00 & 0.0226 & 2.507 & 17 & - & - & - \\
\hline chst13 & Non-normal & Mann-Whitney $U$ test & -1.11 to 0.35 & 0.1520 & - & - & 15 & $0.9953 n=8$ & $0.2621 n=7$ \\
\hline timp1 & Normal & Student's $t$ test & -0.37 to 0.19 & 0.5017 & 0.6946 & 11 & - & - & - \\
\hline timp4 & Non-normal & Mann-Whitney $U$ test & -0.41 to 0.17 & 0.9999 & - & - & 21 & $0.9842 n=6$ & $1.045 n=7$ \\
\hline mmp2 & Normal & Student's $t$ test & -0.60 to -0.004 & 0.0474 & 2.231 & 11 & - & - & - \\
\hline \multirow[t]{3}{*}{$m m p 9$} & Normal & Student's $t$ test & -0.38 to 0.03 & 0.0881 & 1.871 & 11 & - & - & - \\
\hline & \multicolumn{9}{|c|}{ Adult } \\
\hline & $\begin{array}{l}\text { Data } \\
\text { structure }\end{array}$ & Type of test & $\begin{array}{l}\text { Confidence } \\
\text { interval }\end{array}$ & $\mathrm{p}$ value & $t$ statistic & $\begin{array}{l}\text { Degrees of } \\
\text { freedom }\end{array}$ & $U$ score & $\begin{array}{l}\text { Median and } \\
n \text { of vehicle }\end{array}$ & $\begin{array}{l}\text { Median and } \\
n \text { of PNFIx }\end{array}$ \\
\hline aggrecan & Normal & Student's $t$ test & -0.43 to 0.03 & 0.0881 & 1.817 & 16 & - & - & - \\
\hline neurocan & Non-normal & Mann-Whitney $U$ test & -0.34 to 0.94 & 0.3702 & - & - & 37 & $0.9189 n=11$ & $1.014 n=9$ \\
\hline brevican & Normal & Student's $t$ test & -0.17 to 0.65 & 0.2335 & 1.238 & 16 & - & - & - \\
\hline versican & Normal & Student's $t$ test & -0.20 to 0.10 & 0.4973 & 0.6956 & 15 & - & - & - \\
\hline hapln1 & Normal & Student's $t$ test & -0.22 to -0.06 & 0.2205 & 1.275 & 16 & - & - & - \\
\hline hapln2 & Normal & Student's $t$ test & 0.35 to 0.86 & 0.1137 & 1.673 & 16 & - & - & - \\
\hline cspg 4 & Non-normal & Mann-Whitney test & -0.16 to 0.92 & 0.2799 & - & - & 35 & $1.084 n=10$ & $1.118 n=10$ \\
\hline tenascin c & Normal & Student's $t$ test & -0.32 to -0.20 & 0.0054 & 3.219 & 16 & - & - & - \\
\hline tenascin $r$ & Normal & Student's $t$ test & -0.93 to 0.42 & 0.4397 & 0.8507 & 16 & - & - & - \\
\hline has1 & Normal & Student's $t$ test & -0.30 to -0.10 & 0.1810 & 1.399 & 16 & - & - & - \\
\hline has2 & Normal & Student's $t$ test & -0.30 to -0.09 & 0.2027 & 1.328 & 16 & - & - & - \\
\hline has3 & Normal & Student's $t$ test & -0.40 to -0.24 & 0.0129 & 2.797 & 16 & - & - & - \\
\hline chst3 & Non-normal & Mann-Whitney $U$ test & -0.56 to 0.51 & 0.9999 & - & - & 36 & $0.8699 n=9$ & $0.8299 n=8$ \\
\hline chst7 & Non-normal & Mann-Whitney $U$ test & -0.45 to 0.38 & 0.8884 & - & - & 34 & $0.9374 n=9$ & $0.7781 n=8$ \\
\hline chst11 & Normal & Student's $t$ test & -0.62 to 0.48 & 0.7858 & 0.2766 & 15 & - & - & - \\
\hline chst12 & Non-normal & Mann-Whitney $U$ test & -0.50 to 0.28 & 0.6058 & - & - & 30 & $0.8976 n=9$ & $0.7979 n=8$ \\
\hline chst13 & Non-normal & Mann-Whitney $U$ test & -0.85 to 0.42 & 0.6058 & - & - & 30 & $0.8026 n=9$ & $0.8100 n=8$ \\
\hline timp1 & Normal & Student's $t$ test & -0.04 to 0.26 & 0.6473 & 0.4649 & 19 & - & - & - \\
\hline timp4 & Normal & Student's $t$ test & -0.15 to 0.54 & 0.7113 & 0.3760 & 18 & - & - & - \\
\hline$m m p 2$ & Non-normal & Mann-Whitney $U$ test & -0.69 to 1.04 & 0.1564 & - & - & 27 & $1.029 n=9$ & $0.5079 n=10$ \\
\hline mmp9 & Non-normal & Mann-Whitney $U$ test & -0.43 to 0.50 & 0.9742 & - & - & 59 & $0.9411 n=12$ & $0.8429 n=10$ \\
\hline
\end{tabular}

with synthesis of the PNNs (HA synthases, has1, has2, has3, and chondroitin 4-O sulfotransferases, chst3, chst7, chst11, chst12, chst13), as well as pathways linked to proteolytic degradation of PNNs (tissue inhibitor of metalloproteinases, timp1, timp4; and matrix metalloproteinases, $\mathrm{mmp2}$, $\mathrm{mmp9}$; Foscarin et al., 2017; Fawcett et al., 2019). We did not observe any dysregulation in the constituent proteoglycans of PNNs such as aggrecan, brevican, neurocan, versican, and cspg 4 in the hippocampus at either age following PNFIx treatment. However at P21, we did observe a downregulation of mmp2 mRNA $(p=0.0474$, $n=6-7$ per group), a matrix metalloprotease whose role in dendritic remodeling, synaptic plasticity, and axonal sprouting in the hippocampus has been extensively studied (Fujioka et al., 2012). Additionally, we also noted an upregulation in the levels of chst7 $(p=0.0352$, $n=9-10$ per group) and chst 12 transcripts $(p=0.0226$, $n=9-10$ per group), which determines the levels of sulfation of the ECM. In adulthood, we observed significant downregulation in the gene expression of tenascin $c$, a glycoprotein, implicated in hippocampal plasticity (Evers et al., 2002; $p=0.005, n=8-10$ per group). Has3, 


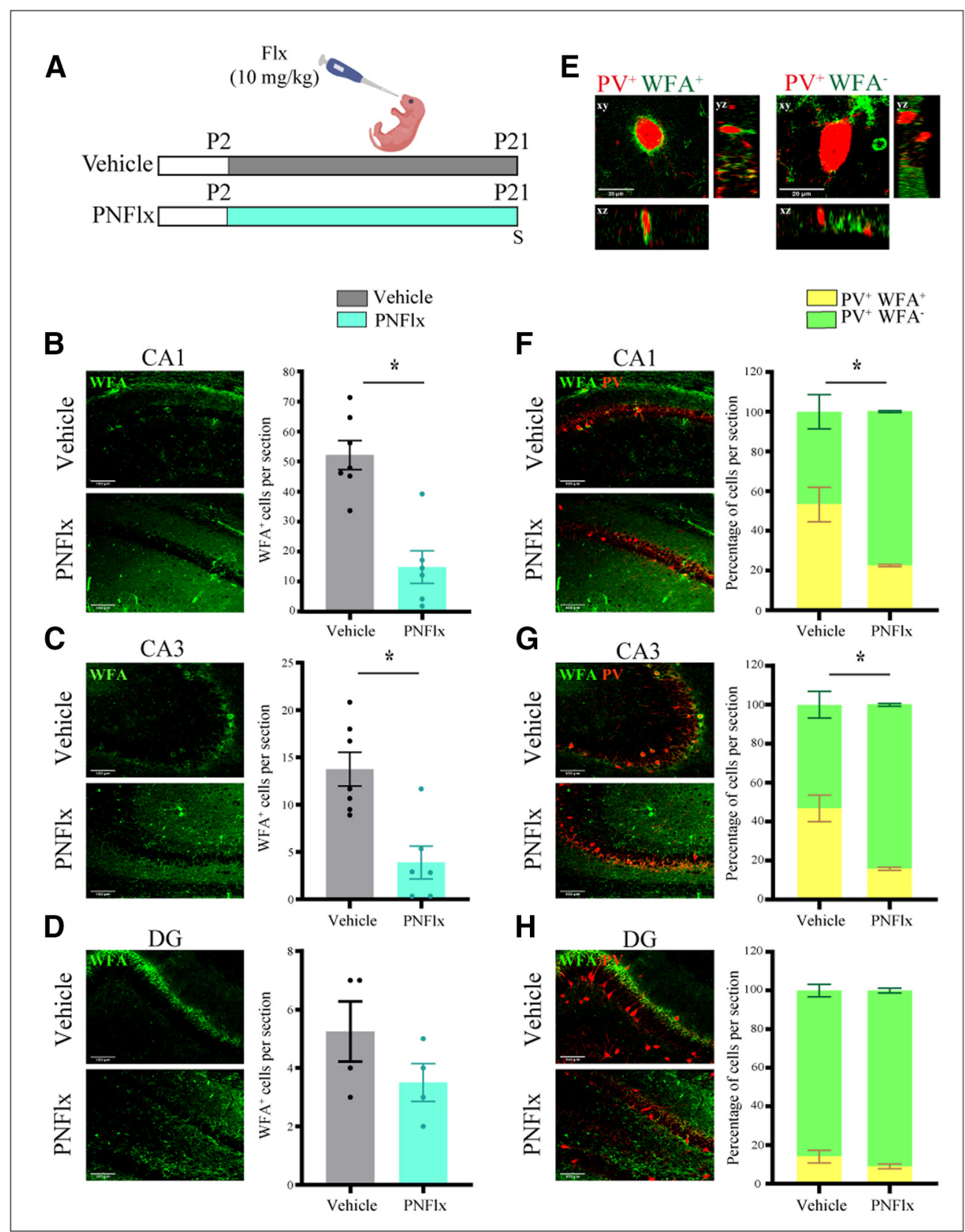

Figure 1. Influence of PNFIx treatment on PNNs in the hippocampus at P21. $\boldsymbol{A}$, Shown is a schematic depicting the experimental paradigm used to test the effects of PNFIx administration from P2 to P21 on hippocampal PNNs. WFA staining was performed to detect PNNs and to assess the number of PV-positive neurons that were surrounded by PNNs. S denotes the age (P21) at which animals were killed. $\boldsymbol{B}$, Shown are representative images and quantification of WFA-positive PNNs in the CA1 hippocampal subfields from vehicle-treated and PNFIx-treated animals at P21. PNNs in the CA1 hippocampal subfields of PNFIx animals showed a significant decline compared with vehicle-treated animals. $\boldsymbol{C}$, Shown are representative images and quantification of WFA-positive PNNs in the CA3 hippocampal subfields from vehicle-treated and PNFIx-treated animals at P21. PNNs in the CA3 hippocampal subfields of PNFIx animals showed a significant decline compared with vehicle-treated animals. $\boldsymbol{D}$, Shown are representative images and quantification of WFA-positive PNNs in the DG hippocampal subfields from vehicle-treated and PNFIx-treated animals at P21. No significant difference was seen in the number of PNNs in the DG hippocampal subfields of vehicle-treated and PNFIx-treated animals at P21. $\boldsymbol{E}$, Shown are representative confocal z-stacks of PV-positive neurons which exhibit the presence (left) or absence (right) of co-localization with a WFA-stained PNN. $\boldsymbol{F}$, Shown are representative double immunofluorescence images of WFA-positive PNNs (green) and PV-positive (red) neurons in the CA1 hippocampal subfields from vehicle-treated and PNFIx-treated animals at P21. Significantly lesser percent of PV-positive cells are surrounded by PNNs in the CA1 hippocampal subfields of PNFIx animals compared with vehicle-treated animals. G, Shown are representative double immunofluorescence images of WFA-positive PNNs (green) and PV-positive (red) neurons in the CA3 hippocampal subfields from vehicle-treated and PNFIx-treated animals at P21. Significantly lesser percent of PV-positive cells are surrounded by PNNs in the CA3 hippocampal subfields of PNFIx animals compared with vehicle-treated animals. $\boldsymbol{H}$, Shown are representative double immunofluorescence images and quantification of WFA- 
continued

positive PNNs (green) and PV-positive (red) neurons in the DG hippocampal subfields from vehicle-treated and PNFIx-treated animals at P21. Quantification revealed no significant difference between the DG hippocampal subfields of vehicle-treated and PNFIxtreated animals at P21. Results are expressed as the mean $\pm \mathrm{SEM}$; ${ }^{*} p<0.05$ as compared with vehicle-treated control animals, two-tailed unpaired Student's $t$ test or Mann-Whitney $U$ test.

an enzyme involved in the synthesis of a critical PNN ECM component, hyaluronan (Fawcett et al., 2019), was also downregulated in the hippocampi of PNFIx animals in adulthood ( $p=0.0129, n=8-10$ per group). Taken together, our data suggest that while PNFIx treatment adversely affects hippocampal PNNs in both a short and long-term manner, there is a limited regulation noted of PNN-associated components at the transcriptional level at these time points.

\section{Influence of PNFIx treatment on interneuron numbers in the hippocampus}

GABAergic interneurons continue to migrate, integrate into circuits, and undergo apoptosis during early postnatal life (Wonders and Anderson, 2006). This temporal window overlaps with the period of PNFIx administration. Interneurons are known to express $5 \mathrm{HT}_{3 \mathrm{~A}}$ receptors and the in vitro migratory patterns of embryonic interneurons have been reported to be affected by serotonergic signaling (Riccio et al., 2009; Puig and Gulledge, 2011). We thus aimed to investigate the effects of PNFIx treatment on hippocampal interneuron numbers at P21 and in adulthood. We performed immunostaining for four major, non-overlapping subclasses of interneurons, that are immunoreactive for SST, PV, CalR, and Reelin.

At P21, we observed no significant difference in the number of SST, PV, CalR, and Reelin-positive interneurons in the hippocampi of PNFIx-treated animals compared with vehicle-treated controls (Fig. 4C,F,I,L). Given we noted a significant decline in the number of PV-positive neurons surrounded by PNNs at P21 in the CA1 hippocampal subfield, this indicates that PNFIx impacts the formation of PNNs but does not influence total PV-positive neuron number. Similarly, in adulthood, the numbers of PV-positive, CalR-positive, and Reelin-positive interneurons present in the CA1, CA3, and DG hippocampal subfields (Fig. $4 D, G, J, M$ ) was not altered by PNFIx treatment. However, we did observe a small but significant increase in the number of SSTpositive neurons in the DG (Fig. 4D), but not the CA subfields, of the hippocampus in adult animals with a history of PNFIx treatment $(p=0.0007, n=3-4$ per group).

Taken together, our results indicate that PNFIx treatment influences the formation of PNNs in the hippocampus during postnatal development. The changes arise in the absence of any major effect on the total numbers of hippocampal SST, PV, CalR, and Reelin-positive interneurons, with the exception of a small but significant increase in SST neuron number in the DG subfield of PNFIx animals in adulthood.

\section{Adult animals with a history of PNFIx treatment exhibit a decline in hippocampal GABA-A $\alpha 2$ expression and enhanced C-Fos expression}

Given we noted changes in PNN numbers following PNFIx treatment accompanied by ECM-associated gene expression changes within the hippocampus, we sought to address whether receptor-subunit switches of the NMDA and GABA receptors, associated with maturation of hippocampal circuitry (Davis et al., 2000; Gambrill and Barria, 2011), are disrupted as a result of PNFIx treatment. PNNs are known to prevent the lateral movement and exchange of transmembrane receptor molecules (Sorg et al., 2016). We examined two classic maturation associated receptor-subunit switches, namely the levels of hippocampal expression of NR2A and NR2B, and GABA$\mathrm{A} \alpha 1$ and GABA-A $\alpha 2$, in vehicle-treated and PNFIx-treated animals at P21 (Fig. 5A-E) and in adulthood (Fig. 5A,F-l). Western blot analysis revealed that NR2A, NR2B, GABAAa1, and GABA-Aa2 protein levels in the hippocampus are unaltered at P21 (Fig. 5B-E). In adulthood, the protein levels of NR2A, NR2B, and GABA-Aa1 remain unchanged (Fig. 5F-l), whereas GABA-Aa2 was significantly reduced within the hippocampi of adult animals with a history of PNFIx treatment ( $p=0.033, n=4$ per group; Fig. $5 H, I)$.

We then addressed whether the altered PNN formation, perturbed gene expression of ECM-associated molecules and dysregulation of GABA-A $\alpha 2$ expression in the hippocampi of PNFIx animals was also associated with any change in baseline neuronal activity levels by assessing the influence of PNFIx on expression of the neuronal activity marker, c-Fos (Bullitt, 1990). Analysis of c-Fos expression in the hippocampus revealed that adult animals with a history of PNFIx treatment exhibited significantly higher numbers of c-Fos-positive cells in the hippocampal CA1 $(p=0.0175, n=7-8$ per group), CA3 $(p=0.0105$, $n=7-8$ per group), and DG ( $p=0.017, n=7-8$ per group) subfields (Fig. $5 J, K$ ). These observations indicate that baseline neuronal activity within the hippocampus is increased in adult animals with a history of PNFIX treatment.

Previous evidence indicates that plasticity of PNNs encapsulating PV-positive neurons can directly impact both excitation and cytoarchitecture of output pyramidal neurons (Orlando et al., 2012). Given that neuronal architecture is known to be strongly correlated with changes in neuronal activity, and is also dependent on the surrounding ECM (Levy et al., 2014), we addressed whether PNFIx treatment led to persistent changes in dendritic morphology of the principal CA1 pyramidal neurons. To address this, we used Golgi-Cox staining to trace the processes of CA1 pyramidal neurons in vehicle-treated and PNFIxtreated adult animals. Sholl analysis revealed a small, but significant, increase in dendritic arbors at the distal-most ends of the apical branches of CA1 pyramidal neurons as 


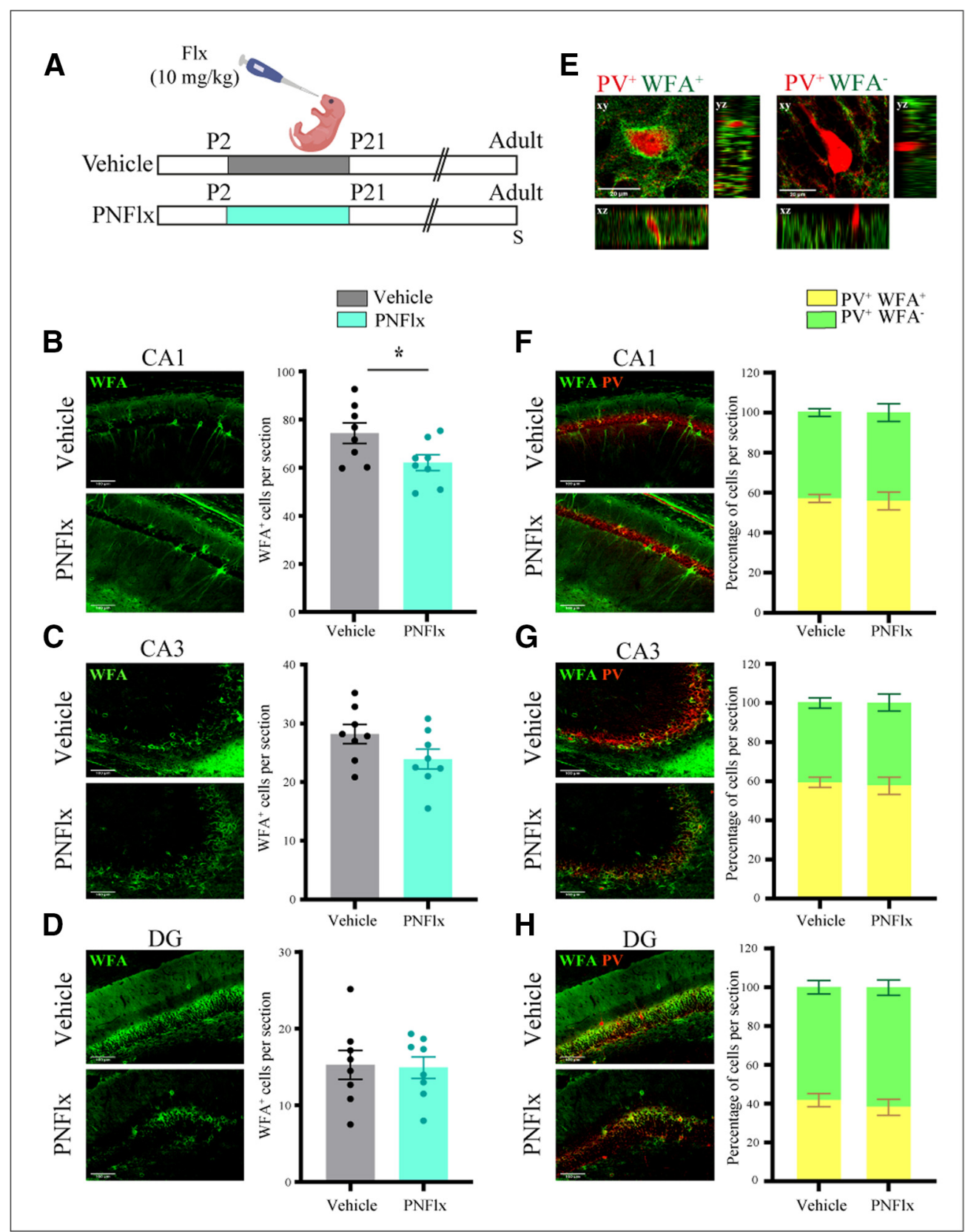

Figure 2. Influence of PNFIx treatment on PNNs in the hippocampus in adulthood. $\boldsymbol{A}$, Shown is a schematic depicting the experimental paradigm used to test the effects of PNFIx administration from P2 to P21 on hippocampal PNNs. WFA staining was performed to detect PNNs and to assess the number of PV-positive neurons that were surrounded by PNNs. S denotes the age (P80) at which animals were killed. $\boldsymbol{B}$, Shown are representative images and quantification of WFA-positive PNNs in the CA1 hippocampal subfields from vehicle-treated and PNFIx-treated adult animals. PNNs in the CA1 hippocampal subfields of PNFIx animals showed a significant decline compared with vehicle-treated animals. $\boldsymbol{C}$, Shown are representative images and quantification of WFA-positive PNNs in the CA3 hippocampal subfields from vehicle-treated and PNFIx-treated adult animals. No significant difference was seen in the number of PNNs in the CA3 hippocampal subfields of vehicle-treated and PNFIx-treated animals in adulthood. $\boldsymbol{D}$, Shown are representative images and quantification of WFA-positive PNNs in the DG hippocampal subfields from PNFIx-treated and vehicletreated adult animals. No significant difference was seen in the number of PNNs in the DG hippocampal subfields of vehicle-treated and PNFIx-treated animals in adulthood. $\boldsymbol{E}$, Shown are representative confocal z-stacks of PV-positive neurons which exhibit the presence (left) or absence (right) of co-localization with a WFA-stained PNN. $\boldsymbol{F}$, Shown are representative double immunofluorescence images and quantification of WFA-positive PNNs (green) and PV-positive (red) neurons in the CA1 hippocampal subfields from vehicle-treated and PNFIx-treated adult animals. G, Shown are representative double immunofluorescence images and quantification of WFA-positive PNNs (green) and PV-positive (red) neurons in the CA3 hippocampal subfields from vehicle-treated and PNFIx-treated adult animals. $\boldsymbol{H}$, Shown are representative double immunofluorescence images and quantification of WFA-positive PNNs (green) and PV-positive (red) neurons in the DG hippocampal subfields from vehicle-treated and PNFIx-treated adult animals. Quantification revealed no significant difference between the CA1, CA3, and DG hippocampal subfields of vehicle-treated and 
continued

PNFIx-treated animals in adulthood. Results are expressed as the mean $\pm \mathrm{SEM} ;{ }^{*} p<0.05$ as compared with vehicle-treated control animals, two-tailed unpaired Student's $t$ test or Mann-Whitney $U$ test.

a consequence of PNFIx treatment $(p<0.0001, n=8-9$ per group; Fig. $5 L-N)$. We have not examined the influence of PNFIx treatment on spine density, or differences in morphology that may be noted at earlier time points.
Collectively, our results indicate that PNFIx treatment evokes a delayed development of PNNs in the hippocampus during the postnatal window and results in persistent changes in neuronal activity, GABA-A receptor subunit composition and CA1 pyramidal neuron dendritic complexity that

\begin{tabular}{|c|c|c|c|c|c|c|c|}
\hline \multirow{5}{*}{$\begin{array}{l}\mathbf{A} \\
\mathbf{B}\end{array}$} & \multirow{2}{*}{\multicolumn{3}{|c|}{ P2 }} & & \multirow{2}{*}{\multicolumn{2}{|c|}{ Adult }} & \\
\hline & & & & P21 & & & \\
\hline & \multirow{2}{*}{\multicolumn{3}{|c|}{ P2 }} & P21 & & \\
\hline & \multirow{2}{*}{\multicolumn{3}{|c|}{ PNFlx $\square$}} & & \multirow{2}{*}{\multicolumn{2}{|c|}{ Adult }} & \\
\hline & & & & s & & & \\
\hline $\begin{array}{l}\text { Gene } \\
\text { category }\end{array}$ & $\begin{array}{l}\text { Gene } \\
\text { name }\end{array}$ & Vehicle & PNFlx & $p$ & Vehicle & PNFlx & $p$ \\
\hline \multirow{9}{*}{$\begin{array}{c}\text { PNN } \\
\text { components }\end{array}$} & aggrecan & $1 \pm 0.181$ & $0.953 \pm 0.070$ & 0.801 & $1 \pm 0.083$ & $0.801 \pm 0.063$ & 0.088 \\
\hline & neurocan & $1 \pm 0.151$ & $0.705 \pm 0.122$ & 0.153 & $1 \pm 0.212$ & $1.587 \pm 0.503$ & 0.264 \\
\hline & brevican & $1 \pm 0.182$ & $0.782 \pm 0.146$ & 0.364 & $1 \pm 0.157$ & $1.240 \pm 0.089$ & 0.233 \\
\hline & versican & $1 \pm 0.114$ & $0.727 \pm 0.120$ & 0.130 & $1 \pm 0.049$ & $0.951 \pm 0.051$ & 0.497 \\
\hline & hapln1 & $1 \pm 0.088$ & $0.888 \pm 0.126$ & 0.497 & $1 \pm 0.070$ & $0.857 \pm 0.090$ & 0.220 \\
\hline & hapln2 & $1 \pm 0.087$ & $0.831 \pm 0.164$ & 0.406 & $1 \pm 0.240$ & $1.604 \pm 0.270$ & 0.114 \\
\hline & $\operatorname{cspg} 4$ & $1 \pm 0.053$ & $0.911 \pm 0.118$ & 0.528 & $1 \pm 0.135$ & $1.489 \pm 0.206$ & 0.057 \\
\hline & tenascinc & $1 \pm 0.214$ & $1.018 \pm 0.141$ & 0.944 & $1 \pm 0.060$ & $0.740 \pm 0.050$ & $0.005^{*}$ \\
\hline & tenascin $r$ & $1 \pm 0.247$ & $0.601 \pm 0.132$ & 0.165 & $1 \pm 0.170$ & $1.190 \pm 0.130$ & 0.407 \\
\hline \multirow{8}{*}{$\begin{array}{c}\text { PNN } \\
\text { synthesis }\end{array}$} & hasl & $1 \pm 0.076$ & $1.026 \pm 0.145$ & 0.884 & $1 \pm 0.110$ & $0.796 \pm 0.087$ & 0.181 \\
\hline & has 2 & $1 \pm 0.061$ & $0.962 \pm 0.113$ & 0.784 & $1 \pm 0.110$ & $0.804 \pm 0.090$ & 0.203 \\
\hline & has 3 & $1 \pm 0.091$ & $0.898 \pm 0.097$ & 0.463 & $1 \pm 0.090$ & $0.680 \pm 0.060$ & $0.013^{*}$ \\
\hline & chst3 & $1 \pm 0.446$ & $1.367 \pm 0.508$ & 0.065 & $1 \pm 0.494$ & $1.130 \pm 0.681$ & 0.999 \\
\hline & chst7 & $1 \pm 0.651$ & $1.679 \pm 0.640$ & $0.035 *$ & $1 \pm 0.728$ & $0.884 \pm 0.390$ & 0.888 \\
\hline & chst 11 & $1 \pm 0.693$ & $1.376 \pm 0.672$ & 0.248 & $1 \pm 0.503$ & $0.928 \pm 0.568$ & 0.786 \\
\hline & chst 12 & $1 \pm 0.470$ & $1.545 \pm 0.476$ & $0.023 *$ & $1 \pm 0.457$ & $1.008 \pm 0.713$ & 0.606 \\
\hline & chst 13 & $1 \pm 0.463$ & $0.898 \pm 0.505$ & 0.153 & $1 \pm 0.852$ & $0.719 \pm 0.503$ & 0.606 \\
\hline \multirow{4}{*}{$\begin{array}{c}\text { PNN } \\
\text { degradation }\end{array}$} & timpl & $1 \pm 0.083$ & $0.912 \pm 0.092$ & 0.502 & $1 \pm 0.149$ & $1.107 \pm 0.178$ & 0.647 \\
\hline & timp4 & $1 \pm 0.054$ & $0.922 \pm 0.106$ & 0.548 & $1 \pm 0.345$ & $1.196 \pm 0.392$ & 0.711 \\
\hline & $m m p 2$ & $1 \pm 0.105$ & $0.697 \pm 0.088$ & $0.047^{*}$ & $1 \pm 0.280$ & $1.323 \pm 0.488$ & 0.563 \\
\hline & $m m p 9$ & $1 \pm 0.083$ & $0.824 \pm 0.051$ & 0.088 & $1 \pm 0.146$ & $1.034 \pm 0.174$ & 0.880 \\
\hline \multicolumn{5}{|c|}{$0.5 \quad 1.0$} & 2.0 & & \\
\hline
\end{tabular}

Figure 3. Transcriptional changes of ECM components in adult animals with a history of postnatal administration of fluoxetine. $\boldsymbol{A}$, Shown is a schematic depicting the experimental paradigm used to test the effects of PNFIx administration from P2 to P21 on expression of PNN associated components in the hippocampus of animals at P21 and adulthood. S denotes the ages (P21 and P100) at which animals were killed. $\boldsymbol{B}$, Shown are the normalized gene expression levels expressed as fold change relative to their agematched vehicle-treated animals, as well as $p$ values calculated using two-tailed, unpaired Student's $t$ test or Mann-Whitney $U$ test ( $n=6-11$ per group). Heat map indicates the extent of gene regulation. Results are expressed as mean \pm SEM (hapln1, hyaluronan and proteoglycan link protein 1; hapln2, hyaluronan and proteoglycan link protein 2; timp1, tissue inhibitor of metalloproteinases 1; timp4, tissue inhibitor of metalloproteinases 4; cspg4, chondroitin sulfate proteoglycan 4; has 1, hyaluronan synthase 1; has2, hyaluronan synthase 2; has3, hyaluronan synthase 3; mmp2, matrix metalloproteinase 2; mmp9, matrix metalloproteinase 9; chst3, carbohydrate sulfotransferase 3; chst7, carbohydrate sulfotransferase 7; chst11, carbohydrate sulfotransferase 11; chst12, carbohydrate sulfotransferase 12; chst13, carbohydrate sulfotransferase 13). 


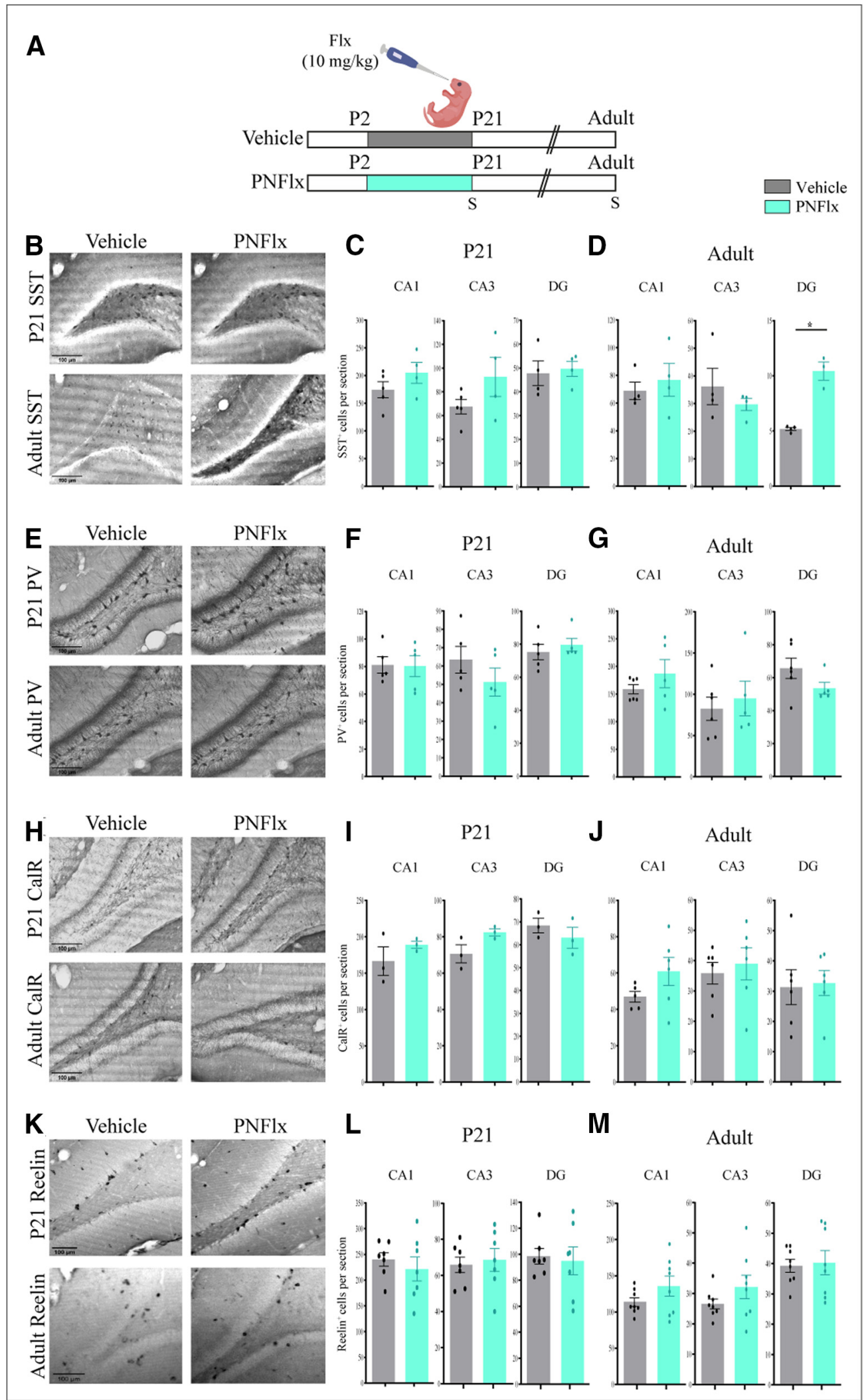

Figure 4. Influence of PNFIx administration on interneuron numbers in the postnatal and adult hippocampus. $\boldsymbol{A}$, Shown is a schematic depicting the experimental paradigm to test effects of PNFIx administration from P2 to P21 on hippocampal interneurons at P21 and adulthood. S denotes the ages (P21 and P80) at which animals were killed. $\boldsymbol{B}$, Shown are representative images of SSTpositive neurons in the hippocampus of PNFIx-treated and vehicle-treated animals at P21 and in adulthood. $\boldsymbol{C}$, Shown is quantification of SST-positive neurons in the CA1, CA3, and DG hippocampal subfields in PNFIx-treated and vehicle-treated control animals 
continued

at P21. Quantification of SST-positive neurons in the CA1, CA3, and DG hippocampal subfields did not show a significant change between PNFIx-treated and vehicle-treated animals at P21. D, Shown is quantification of SST-positive neurons in the CA1, CA3, and DG hippocampal subfields in PNFIx-treated and vehicle-treated animals in adulthood. Quantification of SST-positive neurons showed a significant increase in the DG hippocampal subfield of adult PNFlx-treated animals while no change was observed in the CA1 and CA3 hippocampal subfields. $\boldsymbol{E}$, Shown are representative images of PV-positive neurons in the hippocampus of PNFIxtreated and vehicle-treated animals at P21 and in adulthood. $\boldsymbol{F}$, Shown is quantification of PV-positive neurons in the CA1, CA3, and DG hippocampal subfields in PNFlx-treated and vehicle-treated animals at P21. Quantification of PV-positive neurons in the CA1, CA3, and DG hippocampal subfields did not show a significant change between PNFIx-treated and vehicle-treated animals at P21. G, Shown is quantification of PV-positive neurons in the CA1, CA3, and DG hippocampal subfields in PNFlx-treated and vehicle-treated animals in adulthood. Quantification of PV-positive neurons in the CA1, CA3, and DG hippocampal subfields did not show a significant change between PNFIx-treated and vehicle-treated animals in adulthood. $\boldsymbol{H}$, Shown are representative images of CalR-positive neurons in the hippocampus of PNFIx-treated and vehicle-treated animals at P21 and in adulthood. $I$, Shown is quantification of CalR-positive neurons in the CA1, CA3, and DG hippocampal subfields in PNFIx-treated and vehicle-treated animals at P21. Quantification of CalR-positive neurons in the CA1, CA3, and DG hippocampal subfields did not show a significant change between PNFIx-treated and vehicle-treated animals at P21. J, Shown is quantification of CalR-positive neurons in the CA1, CA3, and DG hippocampal subfields in PNFIx-treated and vehicle-treated animals in adulthood. Quantification of CalR-positive neurons in the CA1, CA3, and DG hippocampal subfields did not show a significant change between PNFlx-treated and vehicle-treated animals in adulthood. $\boldsymbol{K}$, Shown are representative images of Reelin-positive neurons in the hippocampus of PNFIx-treated and vehicle-treated animals at P21 and in adulthood. $L$, Shown is quantification of Reelin-positive neurons in the CA1, CA3, and DG hippocampal subfields in PNFlx-treated and vehicle-treated animals at P21. Quantification of Reelin-positive neurons in the CA1, CA3, and DG hippocampal subfields did not show a significant change between PNFIx-treated and vehicle-treated animals at P21. $\boldsymbol{M}$, Shown is quantification of Reelin-positive neurons in the CA1, CA3, and DG hippocampal subfields in PNFIx-treated and vehicle-treated animals at adulthood. Quantification of Reelin-positive neurons in the CA1, CA3, and DG hippocampal subfields did not show a significant change between PNFIx-treated and vehicle-treated animals in adulthood. All results are expressed as the mean \pm SEM; ${ }^{*} p<0.05$ as compared with vehicle-treated animals, two-tailed unpaired Student's $t$ test or Mann-Whitney $U$ test.

are noted in adulthood long after the cessation of PNFIx treatment.

\section{Influence of PNFIx treatment on interneuron, PNN, and c-Fos-positive cell numbers within the MPFC}

Given that PNFIx treatment evokes subtle changes in SST-positive interneuron numbers, alters the number of PNNs and is associated with perturbed c-Fos expression in the hippocampus, we next sought to investigate whether similar changes occurred within the MPFC, a key limbic region strongly implicated in anxio-depressive behaviors (Covington et al., 2010; Adhikari et al., 2011; Pati et al., 2018). The mPFC transiently expresses the serotonin transporter in the postnatal window (Lebrand et al., 1998) and has been shown to undergo molecular and architectural changes in response to postnatal administration of SSRIs (Rebello et al., 2014). We first assessed the effects of PNFIx treatment on numbers of distinct interneuronal populations, namely SST, PV, and CalR-positive neurons, within the MPFC at P21 and in adulthood. We noted no difference in the number of SST, PV, and CalRpositive interneurons, in the IL, PrL, and $\mathrm{Cg}$ subdivisions of the mPFC at P21 (Fig. 6B,D,F). In adulthood, the number of PV and CalR-positive interneurons were unaltered in the IL, PrL, and $\mathrm{Cg}$ subdivisions of the mPFC (Fig. 6E, $G)$. We did note a small, but significant, decline in the number of SST-positive interneurons in the PrL subdivision of the mPFC in adulthood $(p=0.0216, n=5$ per group; Fig. 6C).

We next sought to investigate the influence of PNFIX treatment on the expression of PNNs in the mPFC. In this regard, we attempted to assess the influence of PNFIx treatment at P21; however, at this developmental stage, it was difficult to visualize and distinguish PNNs in the
mPFC, and hence we have restricted our analysis to the adult time-window. We observed no change in the number of WFA-positive PNNs within the IL, PrL, and Cg (Fig. $6 H$ ) subdivisions of the MPFC between PNFIx-treated and vehicle-treated animals in adulthood (Fig. 6/). We next investigated the influence of PNFIx treatment on baseline neuronal activity via assessing the expression of c-Fospositive cell numbers within the mPFC subdivisions (Fig. $6 J)$. Adult animals with a history of PNFIx treatment exhibited a significant increase in the number of c-Fos-positive cells in the PrL $(p=0.017, n=7-8$ per group; Fig. $6 K)$, and $\mathrm{Cg}(p=0.009, n=7-8$ per group; Fig. $6 K)$, but not the IL, subdivisions of the mPFC. These results indicate that adult animals with a history of PNFIx treatment have enhanced c-Fos-positive cell numbers in the PrL and $\mathrm{Cg}$ mPFC subdivisions suggestive of enhanced neuronal activity in the mPFC.

In summary, we note subtle changes in the number of SST-positive interneuron numbers in both the MPFC and hippocampus, albeit in opposing directions. We also observed that PNFIx treatment evokes perturbed neuronal activity, as reflected by altered c-Fos expression in both the MPFC and the hippocampus in adulthood. These observations motivate future experiments to address whether changes in local microcircuitry within multiple cortical brain regions are persistent long after the cessation of PNFIx treatment.

\section{Discussion}

Here, we have performed a detailed characterization of the short and long-term consequences of PNFIx exposure on PNNs, hippocampal interneuron number and regulation of ECM-related gene expression. We find a significant reduction in PNN numbers within the $\mathrm{CA} 1$ and $\mathrm{CA} 3$ 


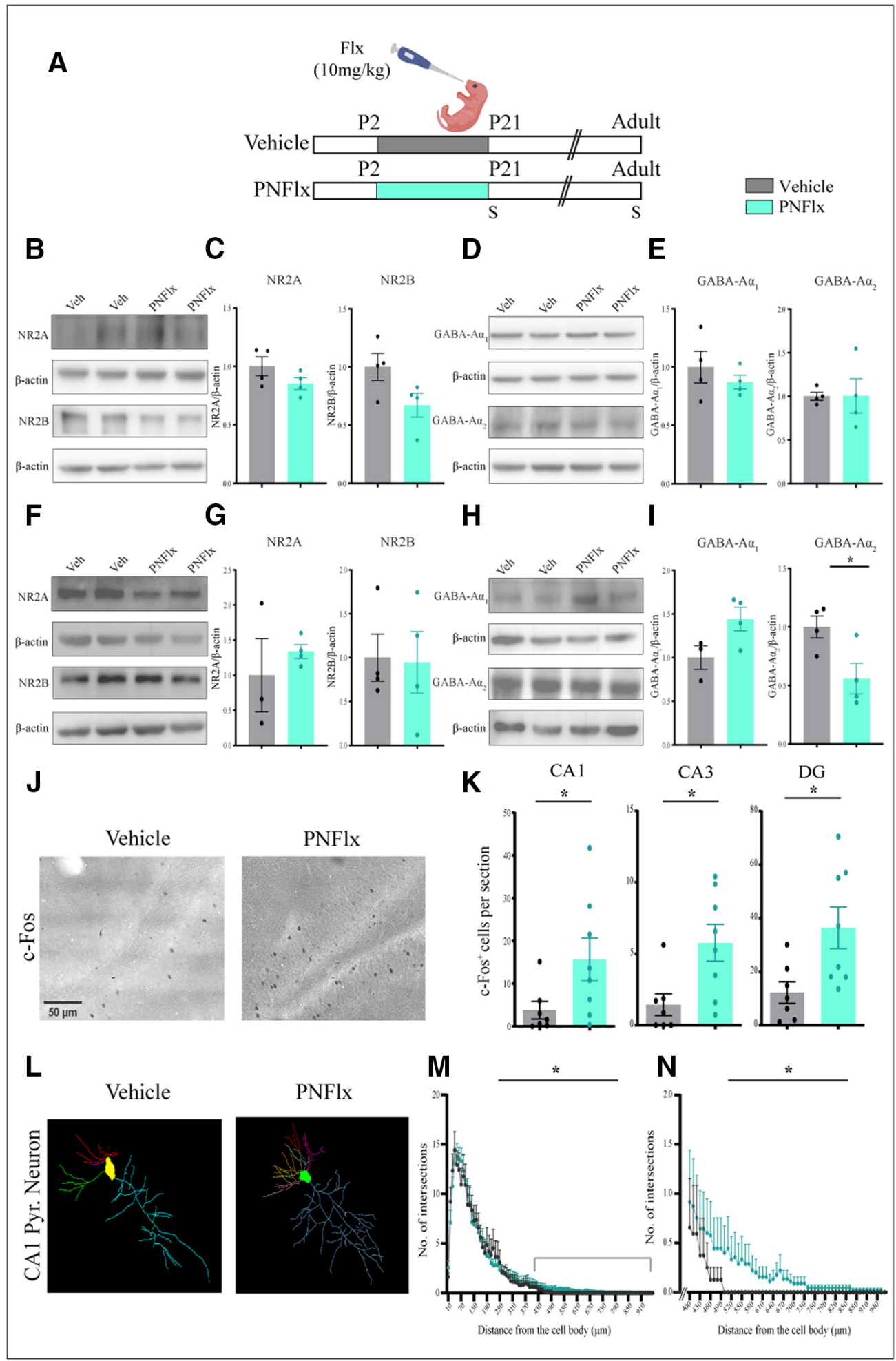

Figure 5. Influence of PNFIx treatment on NMDA and GABA receptor subunit expression, c-Fos-positive cell numbers and CA1 pyramidal neuron morphology in the hippocampus. $\boldsymbol{A}$, Shown is a schematic depicting the experimental paradigm to test the effects of PNFIx administration from P2 to P21 on hippocampal NMDA and GABA receptor subunit expression, c-Fos expression, and architecture of CA1 pyramidal neurons in adult animals. S denotes the age (P21 and P80-P120) at which animals were killed. B, Shown are representative Western blottings of NR2A and NR2B with $\beta$-Actin as the loading control from the hippocampus of vehicle-treated and PNFIx-treated animals at P21. C, Shown are densitometric quantifications of normalized protein levels of NR2A and NR2B. Normalized levels of NR2A and NR2B showed no difference between vehicle-treated and PNFIx-treated animals at P21. $\boldsymbol{D}$, Shown are representative Western blottings of GABA-A $\alpha 1$ and GABA-A $\alpha 2$ with $\beta$-Actin as the loading control from the 
continued

hippocampus of vehicle-treated and PNFIx-treated at P21. E, Shown are densitometric quantification of normalized protein levels of GABA-A $\alpha 1$ and GABA-A $\alpha 2$. Normalized levels of GABA-A $\alpha 1$ and GABA-A $\alpha 2$ showed no difference between vehicle-treated and PNFlx-treated animals at P21. $\boldsymbol{F}$, Shown are representative Western blottings of NR2A and NR2B with $\beta$-Actin as the loading control from the hippocampus of vehicle-treated and PNFIx-treated adult animals. G, Shown are densitometric quantifications of normalized protein levels of NR2A and NR2B. Normalized levels of NR2A and NR2B showed no difference between vehicle-treated and PNFlx-treated animals in adulthood. $\boldsymbol{H}$, Shown are representative Western blottings of GABA-A $\alpha 1$ and GABA-A $\alpha 2$ with $\beta$-Actin as the loading control from the hippocampus of vehicle-treated and PNFIx-treated adult animals. I, Shown are densitometric quantification of normalized protein levels of GABA-A $\alpha 1$ and GABA-A $\alpha 2$. Normalized levels of GABA-A $\alpha 2$ showed a significant decrease in the hippocampus of PNFIx-treated adult animals compared with vehicle-treated adult animals while no significant difference was seen in GABA-A $\alpha 1$ between vehicle-treated and PNFIx-treated animals in adulthood. $\boldsymbol{J}$, Shown are representative images of c-Fos expressing cells in the hippocampus from vehicle-treated and PNFlx-treated animals in adulthood. $\boldsymbol{K}$, Quantifications of c-Fos expressing cells showed a significant increase within the hippocampal subfields of CA1, CA3, and DG in adult PNFIx-treated animals. $\boldsymbol{L}$, Shown are representative traces of Golgi-Cox-stained CA1 hippocampal pyramidal neurons of vehicle-treated and PNFIx-treated adult animals. $\boldsymbol{M}$, Shown is quantification of the number of intersections per micrometer of distance from the soma across the entire apical dendritic arbor in Golgi-Cox-stained hippocampal CA1 pyramidal neurons of PNFIx-treated and vehicle-treated adult animals. $\boldsymbol{N}$, Shown is quantification of the number of intersections per $\mu \mathrm{m}$ distance from the soma across the distal end (400-940 $\mu \mathrm{m})$ of the apical arbors of Golgi-Cox-stained hippocampal CA1 pyramidal neurons of PNFIx-treated and vehicle-treated adult animals. Results for Western blottings, c-Fos immunohistochemistry, total number of intersections of Golgi-Cox-stained CA1 pyramidal neurons are expressed as the mean $\pm \mathrm{SEM} ;{ }^{*} p<0.05$ as compared with vehicle-treated rats using two-tailed, unpaired Student's $t$ test. Results for number of intersections and number of intersections per um distance from the soma of Golgi-Cox-stained CA1 pyramidal neurons are expressed as the mean \pm SEM and PNFIX animals have been compared with vehicle-treated animals using non-parametric repeated measures Friedman's test.

hippocampal subfields, immediately following the cessation of PNFIx treatment at P21, and this decline persists within the CA1 subfield into adulthood. We did not observe any change in the numbers of specific interneuron classes, characterized by the expression of PV, SST, CalR, and Reelin, in the hippocampus at P21. However, we did note a small, but significant, increase in SST-positive interneurons in the DG hippocampal subfield in adulthood in the PNFIx cohort. Our results suggest that PNFIx can influence PNN development in the hippocampus, which is known to exhibit a protracted window of development extending well into postnatal life and adolescence (Bayer, 1980; Rice and Barone, 2000). Given that the temporal window of PNFIx overlaps with substantial neuronal plasticity in terms of interneuron migration, apoptosis, synaptic pruning and synaptogenesis, as well as the formation of PNNs, our results provide an insight into the developmental consequences of enhanced serotonin levels on the maturing hippocampal neurocircuit (Gingrich et al., 2017). Further, we show that PNFIx treatment leads to a reduction in hippocampal GABA-Aa2 receptor subunit protein levels, and an increase in c-Fos expression across all hippocampal subfields in adulthood, suggesting persistent dysregulation of neuronal activity in the hippocampus as a consequence of the early life fluoxetine exposure. This is accompanied by increased dendritic complexity in the distal regions of the apical branches of CA1 pyramidal neurons in adult animals with a history of PNFIx. Collectively, our findings reveal both early-onset and persistent changes in PNN formation, interneuron number, neuronal activity, CA1 pyramidal neuron cytoarchitecture (summarized in Fig. 7) and altered transcriptional regulation of ECM and PNNassociated genes in the hippocampus following PNFIx treatment (Fig. 3B).

Serotonin modulates the development and maturation of neurons during early life (Gaspar et al., 2003). Perturbations in serotonin levels or signaling during this period can lead to developmental, cytoarchitectural as well as behavioral changes that last well into adulthood (Ansorge et al., 2004; Brummelte et al., 2017; Shah et al., 2018). Early-life SSRI administration has been shown to disrupt PNN formation in multiple limbic circuits (Umemori et al., 2015). A previous study showed that administration of fluoxetine in drinking water to pregnant mouse dams, commencing gestational day 7 and extending until P7, which would presumably result in fluoxetine exposure to nursing pups, showed a significant reduction in PNN numbers in the CA1 hippocampal subfield at P17, and exhibited recovery in cohorts of pups examined at P24 (Umemori et al., 2015). While the present study differs substantially in the mode of fluoxetine administration, treatment timeline, species studied and ages examined, it is note-worthy that we also find a robust decline in PNN numbers at the early time point of P21 following PNFIx treatment. At the P21 time point following PNFIx, we have examined PNN numbers, as well as the number of PVpositive interneurons decorated by PNNs, in both male and female pups. However, our studies in adulthood are restricted to males with a history of PNFIx administration, and this is one of the caveats of our study which does not allow us to comment on whether there are any sexually dimorphic effects on PNNs in adult animals with a history of PNFIx. Studies have also shown that chronic administration of SSRIs in adulthood evokes a juvenile-like plasticity in the visual and PFC associated with a dissolution of PNNs (Maya Vetencourt et al., 2008; Ohira et al., 2013; Guirado et al., 2014). PNN formation, primarily around PV-positive interneurons, is thought to be a critical stage that defines the establishment of the maturity, and emerges at distinct developmental epochs in a circuitspecific manner (Köppe et al., 1997; Lensjø et al., 2017). Our findings indicate that the delayed appearance of PNNs following PNFIx treatment results in significantly fewer numbers of PV-positive interneurons ensheathed by PNNs in the CA1 and CA3 hippocampal subfields at P21. This decline is transient, and by adulthood the 


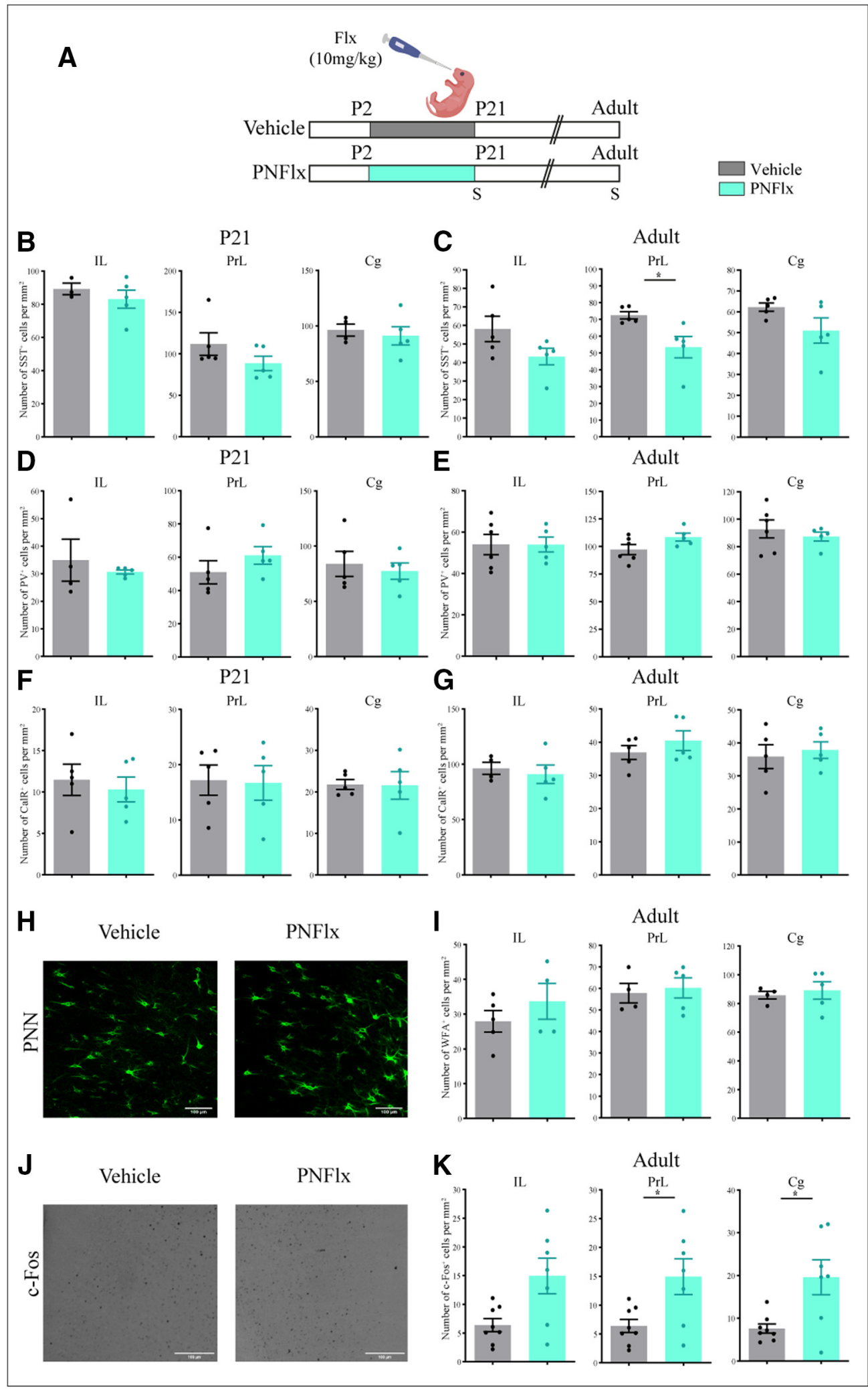

Figure 6. Influence of PNFIx treatment on interneuron numbers, PNNs, and c-Fos-positive cells in the mPFC. $\boldsymbol{A}$, Shown is a schematic depicting the experimental paradigm to test the effects of PNFIx administration from P2 to P21 on interneuron numbers, PNNs, and the number of c-Fos-positive cells. S denotes the age (P21 and P80) at which animals were killed. B, Shown is the quantification of SST-positive neurons in the IL, PrL, and Cg subdivisions of the mPFC in PNFIx-treated and vehicle-treated control animals at P21. C, Shown is the quantification of SST-positive neurons in the IL, PrL, and Cg subdivisions of the mPFC in PNFIxtreated and vehicle-treated control animals at P80. Quantification of SST-positive neurons showed a significant decrease in the PrL 


\section{continued}

subfield of the mPFC in adult PNFlx-treated animals while no change was observed in IL and Cg subdivisions. $\boldsymbol{D}$, Shown is the quantification of PV-positive neurons in the IL, PrL, and $\mathrm{Cg}$ subdivisions of the MPFC in PNFIx-treated and vehicle-treated control animals at P21. $E$, Shown is the quantification of PV-positive neurons in the IL, PrL, and Cg subdivisions of the mPFC in PNFIxtreated and vehicle-treated control animals at P80. $\boldsymbol{F}$, Shown is the quantification of CalR-positive neurons in the IL, PrL, and Cg subdivisions of the mPFC in PNFIx-treated and vehicle-treated control animals at P21. G, Shown is the quantification of CalR-positive neurons in the IL, PrL, and Cg subdivisions of the mPFC in PNFlx-treated and vehicle-treated control animals at P80. $\boldsymbol{H}$, Shown are representative images of WFA-positive PNNs in the $\mathrm{Cg}$ subdivision of the MPFC of PNFIx-treated and vehicle-treated animals in adulthood. I, Shown is the quantification of WFA-positive PNNs in the IL, PrL, and Cg subdivisions of the mPFC in PNFIx-treated and vehicle-treated control animals at P80. J, Shown are representative images of c-Fos-positive cells in the PrL subdivision of the mPFC of PNFIx-treated and vehicle-treated animals in adulthood. $\boldsymbol{K}$, Quantifications of c-Fos-positive cells indicate a significant increase within the PrL, and $\mathrm{Cg}$ subdivisions, with no change noted in the IL, subdivision of the mPFC in adult PNFIx-treated animals. All results are expressed as the mean \pm SEM; ${ }^{*} p<0.05$ as compared with vehicle-treated animals, two-tailed unpaired Student's $t$ test or Mann-Whitney $U$ test.

number of PV-positive interneurons decorated with PNNs is indistinguishable between vehicle-treated and PNFIxtreated animals. However, our results do not allow us to resolve whether the constituent components of the PNN at these timepoints are perturbed. PNNs play an important role in stabilization of synaptic contacts, structural and functional plasticity, and the establishment of E/I balance in neural circuits (Hensch, 2005; Fawcett et al., 2019). Our results clearly indicate that the establishment of PNNs in specific hippocampal subfields is transiently disrupted during postnatal development as a consequence of PNFIx treatment and that this disruption of PNNs persists into adulthood in a hippocampal subfieldspecific manner.

Gene expression analysis revealed that the hippocampal expression of several PNN and ECM-associated genes such as aggrecan, versican, brevican, neurocan, cspg4, and hap/n1-2 do not exhibit any change in expression at either P21 or adulthood following PNFIx treatment. We did however, observe a decrease in $\mathrm{mmp2}$, and an increased expression of chst 7 and chst12 transcript levels immediately postcessation of the PNFIx treatment at P21, and also noted a long-term decline in tenascin $c$ and has 3 mRNA within the hippocampus in adulthood in animals with a history of PNFIx administration. While we cannot draw direct causal links between the transcriptional dysregulation of individual genes to the complex cellular and behavioral phenotypes noted with PNFIx, it is interesting to note that mice constitutively deficient in tenascin $\mathrm{C}$ display compromised LTP in CA1 pyramidal neurons (Evers et al., 2002), and mutant mice that were combinatorial knock-outs of tenascin c, tenascin $r$, brevican, and neurocan were shown to have decreased PNN area and intensity in the CA2 hippocampal subfield (Gottschling et al., 2019). Analyses of interneuron numbers revealed that while the numbers of PV, CalR, and Reelin-positive neurons in the hippocampus do not change as a consequence of PNFIx treatment, we do find a significant increase in the number of SST-positive neurons in the DG of adult animals with a history of PNFIx. Multiple studies indicate that perturbed SST-signaling, and a loss of SSTpositive neurons are both linked to elevated depressivelike/anxiety-like behaviors, and vulnerability of SST neurons to damage has also been suggested in the context of major depressive disorder (Carmichael and Lockhart, 2012; Lin and Sibille, 2015; Douillard-Guilloux et al., 2017;
Fee et al., 2017). Hippocampal SST neurons are also linked to the control of HPA axis activity, with differential effects observed on emotionality based on the class of SST receptors involved (Scheich et al., 2016; Prévôt et al., 2017; Yamamoto et al., 2018). Given the complexity of information processing in hippocampal microcircuitry, it is unclear at present what the consequence of a small increase in SST neuron number in the DG would be on hippocampal function. PNFIx treatment does not appear to result in major disruption of interneuron numbers during postnatal life or in adulthood, however we cannot preclude effects on the cytoarchitecture and function of specific interneuron classes. The decline in PNNs, in particular those that encapsulate PV-positive interneurons, following PNFIx treatment raises the possibility of a disruption of the intrinsic properties of PV-positive interneurons, and hence an impact on the ability of PV-positive interneurons to dynamically gate and adapt their responses to altered neuronal activity (Favuzzi et al., 2017).

Disruption of PNN formation and ECM abnormalities have been linked to the pathophysiology of several psychiatric disorders, including schizophrenia and mood disorders and neurodevelopmental disorders, such as autism spectrum disorder and epilepsy (Pantazopoulos and Berretta, 2016; Wen et al., 2018). Preclinical models of early life trauma that are based on the disruption of dam-pup interactions, such as MS and limited nesting bedding (LNB), perturbed inflammatory milieu evoked via maternal immune activation (MIA) and exposure to juvenile stress have all been reported to evoke a disruption of PNN formation. MS is reported to result in a reduced density of PNNs in the PrL cortex at P20 (Gildawie et al., 2020), and male pups raised by dams in the LNB paradigm exhibit a sexually dimorphic increase in PNN density around PV-positive interneurons within the right basolateral amygdala (Guadagno et al., 2020). Pups born to dams subjected to MIA showed a decline in the density of PNNs in the basolateral amygdala at P35, and in the PrL cortex in adulthood (Paylor et al., 2016). Exposure to juvenile stress is linked to a decrease in the intensity of PNN staining in the CA1 hippocampal subfield, the dorsal anterior Cg cortex, the IL cortex and the motor cortex, immediately following the cessation of the stress (Ueno et al., 2018). Interestingly, MS, LNB, MIA and juvenile stress are all reported to evoke a perturbation of serotonergic signaling (Benekareddy et al., 2010; Luo et al., 2015; Goeden et 


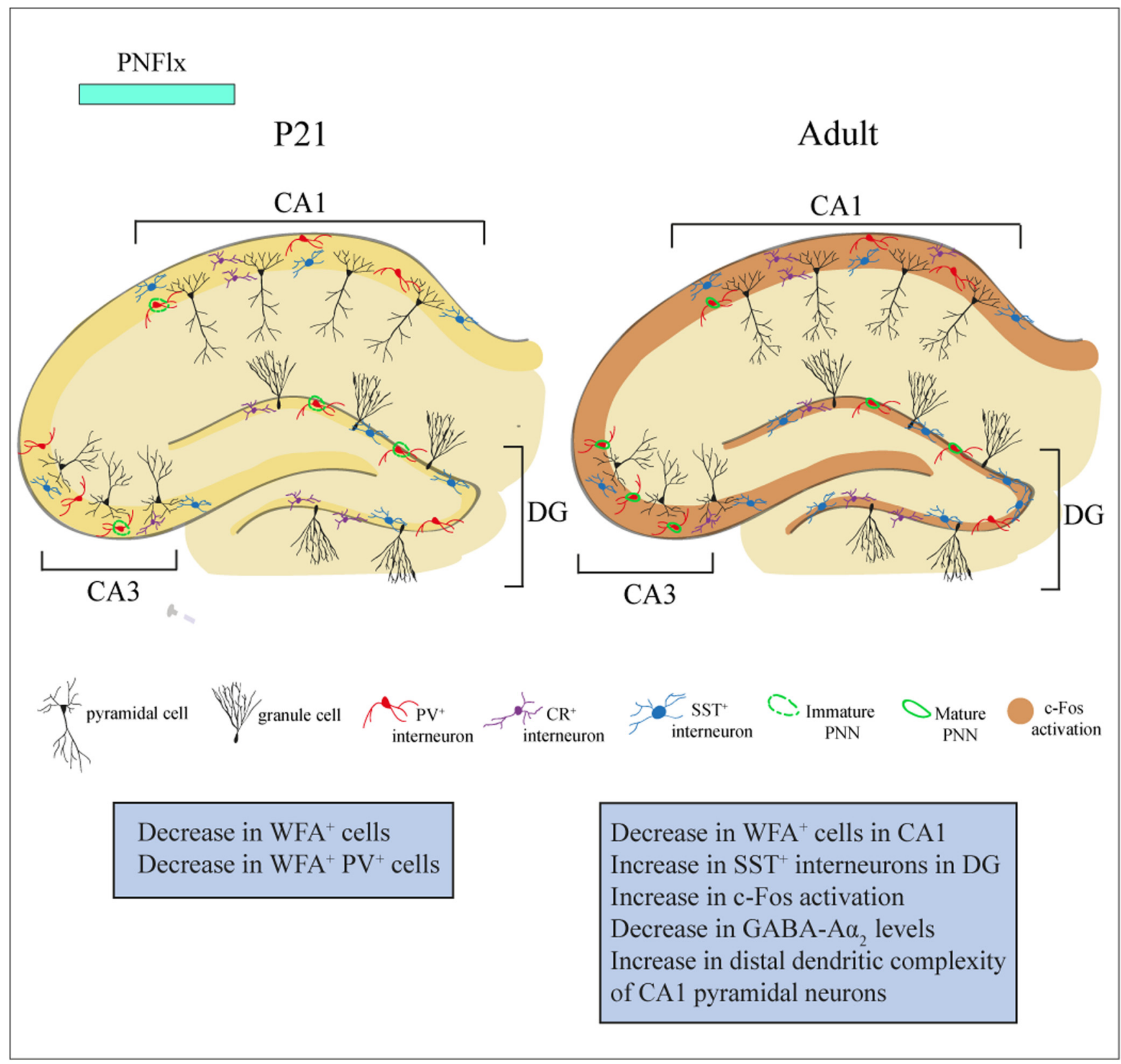

Figure 7. PNFIx treatment causes immediate and long-lasting cellular and molecular changes in the rat hippocampus. PNFIx treatment alters the developmental trajectory of PNN formation within the hippocampus. PNFIx treatment evoked a decline in the number of WFA-positive PNNs, and PV-positive cells ensheathed by WFA-positive PNNs, in the CA1 and CA3 hippocampal subfields at P21. A history of PNFIx treatment was associated with a decline in the number of WFA-positive PNNs in the CA1 hippocampal subfield, and a small increase in the number of SST-positive neurons in the DG hippocampal subfield in adulthood. Adult animals with a history of PNFIx also exhibited an increase in the number of c-Fos-positive cells in all hippocampal subfields, a decline in GABA$\mathrm{A} \alpha 2$ receptor subunit expression within the hippocampus, and enhanced dendritic complexity noted in the distal dendrites of the apical branches of CA1 pyramidal neurons.

al., 2016; Jablonski et al., 2017). These results raise the intriguing possibility that both a perturbation of serotonergic signaling, as well as an altered trajectory of PNN development in key limbic circuits, may be associated with the development of anxiogenic and depressive-like behavioral phenotypes noted in adulthood in these models of early adversity. Our studies suggest that PNFIx treatment, which evokes persistent increases in anxiety-like and despair-like behavior across the life-span, also targets the formation of PNNs in the hippocampus, a brain region implicated in the regulation of mood-related behavior. A disruption of molecular and cellular regulators of plasticity during postnatal maturation has been suggested to be a common signature associated with animal models of depression, based on early adversity exposure, as well as genetic and pharmacological models of neurodevelopmental 
disorders (Fagiolini and Leblanc, 2011; Callaghan et al., 2013; Do et al., 2015; Spijker et al., 2020).

PNN formation and maturation marks the end of the developmental plasticity window in most circuits (Hensch, 2005). A shift in the receptor subunit composition of both NMDA and $\mathrm{GABA}_{A}$ receptor subunits is a hallmark signature associated with neurodevelopment and with the establishment of E/l balance (Davis et al., 2000; Gambrill and Barria, 2011). We find that while the ratio of NR2A NR2B receptor subunits is not altered at P21 or in adult animals with a PNFIx history, we note a robust decline in GABA-A $\alpha 2$ receptor subunit in the hippocampi of PNFIxtreated animals in adulthood. The natural developmental progression indicates a switch from GABA-A $\alpha 2$ to GABA$A \alpha 1$ receptor subunits in adults (Fritschy et al., 1994), and a change in the ratio of specific GABA-A receptor subunits following PNFIx treatment could have an important implication for neuronal activity within the hippocampal circuitry. Indeed, this is reflected in the c-Fos expression analysis which indicates an increase in expression of the neuronal activity marker in all hippocampal subfields of PNFIx animals in adulthood. Interestingly, we also noted an increase in c-Fos expression within the PrL and $\mathrm{Cg}$ subdivisions of the mPFC. Perturbed baseline expression of an immediate early gene marker noted in adulthood in animals with a history of PNFIx administration points to potential disruption of neuronal activity. It will be of interest to also address whether neuronal activity is already perturbed at P21 within the hippocampus and mPFC. Currently, it is difficult to parcellate out whether such a change in neuronal activity in specific limbic brain regions of PNFIx animals is a consequence of mood-related behavioral changes, or whether such altered neuronal activity causally drives the behavioral changes noted with PNFIx. A limitation of our study is that the identity of neurons that are c-Fos-positive is unclear, and hence it remains unknown at present whether animals with a history of PNFIx exhibit enhanced neuronal firing in excitatory or inhibitory neurons within the hippocampus and the mPFC. Our findings motivate further studies to directly test the consequences of PNFIx evoked altered PNN development on the neuronal activity and intrinsic properties of PV-positive interneurons, and on the emergence of E/I balance within the hippocampus and mPFC.

Serotonin is known to modulate neuronal morphology, and dendritic spine shape/density (Daubert and Condron, 2010; Bijata et al., 2017; Wirth et al., 2017). PNFIx treatment from P2 to P11 results in decreased dendritic arbor complexity in pyramidal neurons of the IL cortex (Rebello et al., 2014). In contrast, a developmental knock-out of the serotonin transporter is associated with increased dendritic complexity in IL pyramidal neurons, and an increase in spine density in pyramidal neurons of the basolateral amygdala (Wellman et al., 2007). We noted a subtle increase in dendritic complexity, restricted to the distalmost regions of the apical dendrites of CA1 pyramidal neurons in PNFIx-treated animals in adulthood. Hippocampal gene expression changes associated with PNFIx indicate dysregulation of pathways that modulate neuronal cytoarchitecture, namely mTOR signaling, and perturbed gene expression of the hyperpolarization-activated cyclic nucleotide-gated 1 channel (Hcn1), which is known to exhibit distal dendrite enrichment (Sarkar et al., 2014b). While we have not extensively examined the influence of PNFIx on spine number, shape and density in hippocampal pyramidal neurons, our observations motivate a detailed characterization of the impact of early life serotonin elevation on the cytoarchitecture of distinct neuronal classes within the hippocampus.

Collectively, our findings indicate that early life elevation of serotonin via treatment with the SSRI fluoxetine alters the developmental trajectory of PNNs within the hippocampus, suggestive of a disruption of critical period plasticity. This evidence supports an emerging body of literature that implicates disruption of PNNs and ECM dysregulation as putative mechanisms that contribute to the circuit dysfunction associated with psychiatric and neurodevelopmental disorders.

\section{References}

Adhikari A, Topiwala MA, Gordon JA (2011) Single units in the medial prefrontal cortex with anxiety-related firing patterns are preferentially influenced by ventral hippocampal activity. Neuron 71:898910.

Ansorge MS, Zhou M, Lira A (2004) Early-life blockade of the 5-HT transporter alters emotional behavior in adult mice. Science 306:879-881.

Ansorge MS, Morelli E, Gingrich JA (2008) Inhibition of serotonin but not norepinephrine transport during development produces delayed, persistent perturbations of emotional behaviors in mice. $J$ Neurosci 28:199-207.

Bath KG, Manzano-Nieves G, Goodwill H (2016) Early life stress accelerates behavioral and neural maturation of the hippocampus in male mice. Horm Behav 82:64-71.

Bayer SA (1980) Development of the hippocampal region in the rat II. Morphogenesis during embryonic and early postnatal life. J Comp Neurol 190:115-134.

Benekareddy M, Goodfellow NM, Lambe EK, Vaidya VA (2010) Enhanced function of prefrontal serotonin 5-HT(2) receptors in a rat model of psychiatric vulnerability. J Neurosci 30:12138-12150.

Bijata M, Labus J, Guseva D, Stawarski M, Butzlaff M, Dzwonek J, Schneeberg J, Böhm K, Michaluk P, Rusakov DA, Dityatev A, Wilczyński G, Wlodarczyk J, Ponimaskin E (2017) Synaptic remodeling depends on signaling between serotonin receptors and the extracellular matrix. Cell Rep 19:1767-1782.

Bond CM, Johnson JC, Chaudhary V, McCarthy EM, McWhorter ML, Woehrle NS (2020) Perinatal fluoxetine exposure results in social deficits and reduced monoamine oxidase gene expression in mice. Brain Res 1727:146282.

Brückner G, Bringmann A, Köppe G, Härtig W, Brauer K (1996) In vivo and in vitro labelling of perineuronal nets in rat brain. Brain Res 720:84-92.

Brummelte S, Mc Glanaghy E, Bonnin A, Oberlander TF (2017) Developmental changes in serotonin signaling: implications for early brain function, behavior and adaptation. Neuroscience 342:212-231.

Bullitt E (1990) Expression of C-fos-like protein as a marker for neuronal activity following noxious stimulation in the rat. J Comp Neurol 296:517-530.

Callaghan BL, Graham BM, Li S, Richardson R (2013) From resilience to vulnerability: mechanistic insights into the effects of stress on transitions in critical period plasticity. Front Psychiatry 4:90-15.

Carmichael O, Lockhart S (2012) The role of diffusion tensor imaging in the study of cognitive aging. Curr Top Behav Neurosci 11:289320. 
Champagne DL, Bagot RC, Van Hasselt F, Ramakers G, Meaney MJ, De Kloet ER, Joëls M, Krugers H (2008) Maternal care and hippocampal plasticity: evidence for experience-dependent structural plasticity, altered synaptic functioning, and differential responsiveness to glucocorticoids and stress. J Neurosci 28:6037-6045.

Chen Y, Baram TZ (2016) Toward understanding how early-life stress reprograms cognitive and emotional brain networks. Neuropsychopharmacology 41:197-206.

Cipriani A, Barbui C, Geddes JR (2005) Suicide, depression, and antidepressants. BMJ 330:373-374.

Covington HE, Lobo MK, Maze I, Vialou V, Hyman JM, Zaman S, LaPlant Q, Mouzon E, Ghose S, Tamminga CA, Neve RL, Deisseroth K, Nestler EJ (2010) Antidepressant effect of optogenetic stimulation of the medial prefrontal cortex. J Neurosci 30:16082-16090.

Daubert EA, Condron BG (2010) Serotonin: a regulator of neuronal morphology and circuitry. Trends Neurosci 33:424-434.

Davis AM, Penschuck S, Fritschy JM, McCarthy MM (2000) Developmental switch in the expression of GABA(A) receptor subunits $\alpha 1$ and $\alpha 2$ in the hypothalamus and limbic system of the rat. Brain Res Dev Brain Res 119:127-138.

Do KQ, Cuenod M, Hensch TK (2015) Targeting oxidative stress and aberrant critical period plasticity in the developmental trajectory to schizophrenia. Schizophr Bull 41:835-846.

Douillard-Guilloux G, Lewis D, Seney ML, Sibille E (2017) Decrease in somatostatin-positive cell density in the amygdala of females with major depression. Depress Anxiety 34:68-78.

Evers MR, Salmen B, Bukalo O, Rollenhagen A, Bösl MR, Morellini F, Bartsch U, Dityatev A, Schachner M (2002) Impairment of L-type $\mathrm{Ca} 2+$ channel-dependent forms of hippocampal synaptic plasticity in mice deficient in the extracellular matrix glycoprotein tenascin-C. J Neurosci 22:7177-7194.

Fagiolini M, Leblanc JJ (2011) Autism: a critical period disorder? Neural Plast 2011:921680.

Favuzzi E, Marques-Smith A, Deogracias R, Winterflood CM, Sánchez-Aguilera A, Mantoan L, Maeso P, Fernandes C, Ewers H, Rico B (2017) Activity-dependent gating of parvalbumin interneuron function by the perineuronal net protein brevican. Neuron 95:639-655.e10.

Fawcett JW, Oohashi T, Pizzorusso T (2019) The roles of perineuronal nets and the perinodal extracellular matrix in neuronal function. Nat Rev Neurosci 20:451-465.

Fee C, Banasr M, Sibille E (2017) Somatostatin-positive gamma-aminobutyric acid interneuron deficits in depression: cortical microcircuit and therapeutic perspectives. Biol Psychiatry 82:549-559.

Fenoglio KA, Brunson KL, Baram TZ (2006) Hippocampal neuroplasticity induced by early-life stress: functional and molecular aspects. Front Neuroendocrinol 27:180-192.

Foscarin S, Raha-Chowdhury R, Fawcett JW, Kwok JCF (2017) Brain ageing changes proteoglycan sulfation, rendering perineuronal nets more inhibitory. Aging (Albany NY) 9:1607-1622.

Fritschy JM, Paysan J, Enna A, Mohler H (1994) Switch in the expression of rat $\mathrm{GABA}(\mathrm{A})$-receptor subtypes during postnatal development: an immunohistochemical study. J Neurosci 14:5302-5324.

Fujioka H, Dairyo Y, Yasunaga KI, Emoto K (2012) Neural functions of matrix metalloproteinases: plasticity, neurogenesis, and disease. Biochem Res Int 2012:789083.

Gambrill AC, Barria A (2011) NMDA receptor subunit composition controls synaptogenesis and synapse stabilization. Proc Natl Acad Sci USA 108:5855-5860.

Gaspar P, Cases O, Maroteaux L (2003) The developmental role of serotonin: news from mouse molecular genetics. Nat Rev Neurosci 4:1002-1012.

Gemmel M, Rayen I, Lotus T, van Donkelaar E, Steinbusch HW, de Lacalle S, Kokras N, Dalla C, Pawluski JL (2016) Developmental fluoxetine and prenatal stress effects on serotonin, dopamine, and synaptophysin density in the PFC and hippocampus of offspring at weaning. Dev Psychobiol 58:315-327.

Gildawie KR, Honeycutt JA, Brenhouse HC (2020) Region-specific effects of maternal separation on perineuronal net and parvalbumin-expressing interneuron formation in male and female rats. Neuroscience 428:23-37.

Gingrich JA, Malm H, Ansorge MS, Brown A, Sourander A, Suri D, Teixeira CM, Caffrey Cagliostro MK, Mahadevia D, Weissman MM (2017) New insights into how serotonin selective reuptake inhibitors shape the developing brain. Birth Defects Res 109:924-932.

Glover ME, Clinton SM (2016) Of rodents and humans: a comparative review of the neurobehavioral effects of early life SSRI exposure in preclinical and clinical research. Int J Dev Neurosci 51:50-72.

Goeden N, Velasquez J, Arnold KA, Chan Y, Lund BT, Anderson GM, Bonnin A (2016) Maternal inflammation disrupts fetal neurodevelopment via increased placental output of serotonin to the fetal brain. J Neurosci 36:6041-6049.

Gottschling C, Wegrzyn D, Denecke B, Faissner A (2019) Elimination of the four extracellular matrix molecules tenascin- $C$, tenascin- $R$, brevican and neurocan alters the ratio of excitatory and inhibitory synapses. Sci Rep 9:13939.

Guadagno A, Verlezza S, Long H, Wong TP, Walkerl CD (2020) It is all in the right amygdala: increased synaptic plasticity and perineuronal nets in male, but not female juvenile rat pups after exposure to early-life stress. J Neuroendocrinol 40:8276-8291.

Guirado R, Perez-Rando M, Sanchez-Matarredona D, Castrén E, Nacher J (2014) Chronic fluoxetine treatment alters the structure, connectivity and plasticity of cortical interneurons. Int $\mathrm{J}$ Neuropsychopharmacol 17:1635-1646.

Hensch TK (2004) Critical period regulation. Annu Rev Neurosci 27:549-579.

Hensch TK (2005) Critical period plasticity in local cortical circuits. Nat Rev Neurosci 6:877-888.

Hilakivi LA, Hilakivi I (1987) Increased adult behavioral "despair" in rats neonatally exposed to desipramine or zimeldine: an animal model of depression? Pharmacol Biochem Behav 28:367-369.

Hilakivi LA, Taira T, Hilakivi I (1988) Early postnatal deprivation of active sleep with desipramine or zimeldine impairs later behavioural reactivity to auditory stimuli in rats. Acta Physiol Scand 132:191198.

Jablonski SA, Graham DL, Vorhees CV, Williams MT (2017) Effects of neonatal methamphetamine and stress on brain monoamines and corticosterone in preweanling rats. Neurotox Res 31:269-282.

Karpova NN, Lindholm J, Pruunsild P, Timmusk T, Castrén E (2009) Long-lasting behavioural and molecular alterations induced by early postnatal fluoxetine exposure are restored by chronic fluoxetine treatment in adult mice. Eur Neuropsychopharmacol 19:97108.

Karpova NN, Pickenhagen A, Lindholm J, Tiraboschi E, Kulesskaya N, Agústsdóttir A, Antila H, Popova D, Akamine Y, Bahi A, Sullivan R, Hen R, Drew LJ, Castrén E (2011) Fear erasure in mice requires synergy between antidepressant drugs and extinction training. Science 334:1731-1734.

Kodish I, Rockhill C, Varley C (2011) Pharmacotherapy for anxiety disorders in children and adolescents. Dialogues Clin Neurosci 13:439-452.

Köppe G, Brückner G, Brauer K, Härtig W, Bigl V (1997) Developmental patterns of proteoglycan-containing extracellular matrix in perineuronal nets and neuropil of the postnatal rat brain. Cell Tissue Res 288:33-41.

Lebrand C, Cases O, Wehrlé R, Blakely RD, Edwards RH, Gaspar P (1998) Transient developmental expression of monoamine transporters in the rodent forebrain. J Comp Neurol 401:506-524.

Lensjø KK, Lepperød ME, Dick G, Hafting T, Fyhn M (2017) Removal of perineuronal nets unlocks juvenile plasticity through network mechanisms of decreased inhibition and increased gamma activity. J Neurosci 37:1269-1283.

Levy AD, Omar MH, Koleske AJ (2014) Extracellular matrix control of dendritic spine and synapse structure and plasticity in adulthood. Front Neuroanat 8:116-118.

Lin LC, Sibille E (2015) Somatostatin, neuronal vulnerability and behavioral emotionality. Mol Psychiatry 20:377-387.

Lipachev N, Arnst N, Melnikova A, Jäälinoja H, Kochneva A, Zhigalov A, Kulesskaya N, Aganov AV, Mavlikeev M, Rauvala H, Kiyasov 
AP, Paveliev M (2019) Quantitative changes in perineuronal nets in development and posttraumatic condition. J Mol Histol 50:203216.

Luo J, Min S, Wei K, Cao J, Wang B, Li P, Dong J, Liu Y (2015) Behavioral and molecular responses to electroconvulsive shock differ between genetic and environmental rat models of depression. Psychiatry Res 226:451-460.

Maya Vetencourt JF, Sale A, Viegi A, Baroncelli L, De Pasquale R, O'Leary OF, Castrén E, Maffei L (2008) The antidepressant fluoxetine restores plasticity in the adult visual cortex. Science 320:385388.

Mirmiran M, Van De Poll NE, Corner MA, van Oyen HG, Bour HL (1981) Suppression of active sleep by chronic treatment with chlorimipramine during early postnatal development: effects upon adult sleep and behavior in rat. Brain Re 204:129-146.

Mulder EJH, Ververs FFT, De Heus R, Visser GHA (2011) Selective serotonin reuptake inhibitors affect neurobehavioral development in the human fetus. Neuropsychopharmacology 36:1961-1971.

Murthy S, Kane GA, Katchur NJ, Lara Mejia PS, Obiofuma G, Buschman TJ, McEwen BS, Gould E (2019) Perineuronal nets, inhibitory interneurons, and anxiety-related ventral hippocampal neuronal oscillations are altered by early life adversity. Biol Psychiatry 85:1011-1020.

Naninck EFG, Hoeijmakers L, Kakava-Georgiadou N, Meesters A, Lazic SE, Lucassen PJ, Korosi A (2015) Chronic early life stress alters developmental and adult neurogenesis and impairs cognitive function in mice. Hippocampus 25:309-328.

Nonacs R, Cohen LS (2003) Assessment and treatment of depression during pregnancy: an update. Psychiatr Clin North Am 26:547-562.

Norcross M, Mathur P, Poonam M, Enoch AJ, Karlsson R-M, Brigman JL, Cameron HA, Harvey-White J, Holmes A (2008) Effects of adolescent fluoxetine treatment on fear-, anxiety- or stress-related behaviors in C57BL/6J or BALB/cJ mice. Psychopharmacology (Berl) 200:413-424.

Ohira K, Takeuchi R, Iwanaga T, Miyakawa T (2013) Chronic fluoxetine treatment reduces parvalbumin expression and perineuronal nets in gamma-aminobutyric acidergic interneurons of the frontal cortex in adult mice. Mol Brain 6:43-11.

Oleskevich S, Descarries L (1990) Quantified distribution of the serotonin innervation in adult rat hippocampus. Neuroscience 34:1933.

Orlando C, Ster J, Gerber U, Fawcett JW, Raineteau O (2012) Perisynaptic chondroitin sulfate proteoglycans restrict structural plasticity in an integrin-dependent manner. J Neurosci 32:1800918017.

Pantazopoulos H, Berretta S (2016) In sickness and in health: perineuronal nets and synaptic plasticity in psychiatric disorders. Neural Plast 2016:9847696.

Pati S, Sood A, Mukhopadhyay S, Vaidya VA (2018) Acute pharmacogenetic activation of medial prefrontal cortex excitatory neurons regulates anxiety-like behaviour. J Biosci 43:85-95.

Paylor JW, Lins BR, Greba Q, Moen N, De Moraes RS, Howland JG, Winship IR (2016) Developmental disruption of perineuronal nets in the medial prefrontal cortex after maternal immune activation. Sci Rep 6:37580-37511.

Pizzorusso T, Medini P, Berardi N, Chierzi S, Fawcett JW, Maffei L (2002) Reactivation of ocular dominance plasticity in the adult visual cortex. Science 298:1248-1251.

Popa D, Léna C, Alexandre C, Adrien J (2008) Lasting syndrome of depression produced by reduction in serotonin uptake during postnatal development: evidence from sleep, stress, and behavior. J Neurosci 28:3546-3554.

Prévôt TD, Gastambide F, Viollet C, Henkous N, Martel G, Epelbaum J, Béracochéa D, Guillou JL (2017) Roles of hippocampal somatostatin receptor subtypes in stress response and emotionality. Neuropsychopharmacology 42:1647-1656.

Puig MV, Gulledge AT (2011) Serotonin and prefrontal cortex function: neurons, networks, and circuits. Mol Neurobiol 44:449-464.
Rayen I, Gemmel M, Pauley G, Steinbusch HWM, Pawluski JL (2015) Developmental exposure to SSRIs, in addition to maternal stress, has long-term sex-dependent effects on hippocampal plasticity. Psychopharmacology (Berl) 232:1231-1244.

Rebello TJ, Yu Q, Caffrey Cagliostro MK, Teissier A, Morelli E, Demireva EY, Chemiakine A, Rosoklija GB, Dwork AJ, Gingrich JA, Ansorge MS, Goodfellow NM, Lambe EK, Rosoklija GB, Dwork AJ, Gingrich JA, Ansorge MS, Rosoklija GB, Dwork AJ (2014) Postnatal day 2 to 11 constitutes a 5-HT-sensitive period impacting adult mPFC function. J Neurosci 34:12379-12393.

Riccio O, Potter G, Walzer C, Vallet P, Szabó G, Vutskits L, Kiss JZ, Dayer AG (2009) Excess of serotonin affects embryonic interneuron migration through activation of the serotonin receptor 6 . Mol Psychiatry 14:280-290.

Rice D, Barone S (2000) Critical periods of vulnerability for the developing nervous system: evidence from humans and animal models. Environ Health Perspect 108:511-533.

Sarkar A, Chachra P, Kennedy P, Pena CJ, Desouza LA, Nestler EJ, Vaidya VA (2014a) Hippocampal HDAC4 contributes to postnatal fluoxetine-evoked depression-like behavior. Neuropsychopharmacology 39:2221-2232.

Sarkar A, Chachra P, Vaidya VA (2014b) Postnatal fluoxetine-evoked anxiety is prevented by concomitant $5-\mathrm{HT} 2 \mathrm{~A} / \mathrm{C}$ receptor blockade and mimicked by postnatal $5-\mathrm{HT} 2 \mathrm{~A} / \mathrm{C}$ receptor stimulation. Biol Psychiatry 76:858-868.

Scheich B, Gaszner B, Kormos V, László K, Ádori C, Borbély É, Hajna Z, Tékus V, Bölcskei K, Ábrahám I, Pintér E, Szolcsányi J, Helyes Z (2016) Somatostatin receptor subtype 4 activation is involved in anxiety and depression-like behavior in mouse models. Neuropharmacology 101:204-215.

Shah R, Courtiol E, Castellanos FX, Teixeira CM (2018) Abnormal serotonin levels during perinatal development lead to behavioral deficits in adulthood. Front Behav Neurosci 12:114-110.

Simpson KL, Weaver KJ, De Villers-Sidani E, Lu JYF, Cai Z, Pang Y, Rodriguez-Porcel F, Paul IA, Merzenich M, Lin RCS (2011) Perinatal antidepressant exposure alters cortical network function in rodents. Proc Natl Acad Sci USA 108:18465-18470.

Sorg BA, Berretta S, Blacktop JM, Fawcett JW, Kitagawa H, Kwok JCF, Miquel M (2016) Casting a wide net: role of perineuronal nets in neural plasticity. J Neurosci 36:11459-11468.

Spijker S, Koskinen MK, Riga D (2020) Incubation of depression: ECM assembly and parvalbumin interneurons after stress. Neurosci Biobehav Rev 118:65-79.

Suri D, Bhattacharya A, Vaidya VA (2014) Early stress evokes temporally distinct consequences on the hippocampal transcriptome, anxiety and cognitive behaviour. Int $\mathrm{J}$ Neuropsychopharmacol 17:289-301.

Svirsky N, Levy S, Avitsur R (2016) Prenatal exposure to selective serotonin reuptake inhibitors (SSRI) increases aggression and modulates maternal behavior in offspring mice. Dev Psychobiol 58:7182.

Ueno H, Suemitsu S, Murakami S, Kitamura N, Wani K, Matsumoto Y, Okamoto M, Aoki S, Ishihara T (2018) Juvenile stress induces behavioral change and affects perineuronal net formation in juvenile mice. BMC Neurosci 19:41.

Umemori J, Winkel F, Castrén E, Karpova NN (2015) Distinct effects of perinatal exposure to fluoxetine or methylmercury on parvalbumin and perineuronal nets, the markers of critical periods in brain development. Int J Dev Neurosci 44:55-64.

Vogel G, Neill D, Hagler M, Kors D (1990) A new animal model of endogenous depression: a summary of present findings. Neurosci Biobehav Rev 14:85-91.

Weaver KJ, Paul IA, Lin RCS, Simpson KL (2010) Neonatal exposure to citalopram selectively alters the expression of the serotonin transporter in the hippocampus: dose-dependent effects. Anat Rec (Hoboken) 293:1920-1932.

Wellman CL, Izquierdo A, Garrett JE, Martin KP, Carroll J, Millstein R, Lesch KP, Murphy DL, Holmes A (2007) Impaired stress-coping and fear extinction and abnormal corticolimbic morphology in serotonin transporter knock-out mice. J Neurosci 27:684-691. 
Wen TH, Binder DK, Ethell IM, Razak KA (2018) The perineuronal 'safety' net? Perineuronal net abnormalities in neurological disorders. Front Mol Neurosci 11:270-217.

Wirth A, Holst K, Ponimaskin E (2017) How serotonin receptors regulate morphogenic signalling in neurons. Prog Neurobiol 151:35-56.
Wonders CP, Anderson SA (2006) The origin and specification of cortical interneurons. Nat Rev Neurosci 7:687-696.

Yamamoto M, Ding $Y$, Melmed S, Yamamoto $M$, Ben-shlomo A, Kameda H, Fukuoka H, Deng N (2018) Somatostatin receptor subtype 5 modifies hypothalamic-pituitary-adrenal axis stress function. JCl Insight 3:e122932. 